\title{
Agroecología en el Ecuador. Proceso histórico, logros, y desafíos
}

\author{
Roberto Gortaire A. *
}

\begin{abstract}
RESUMEN

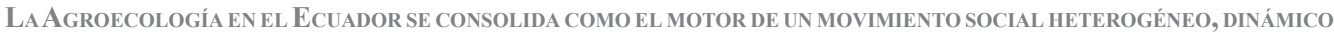

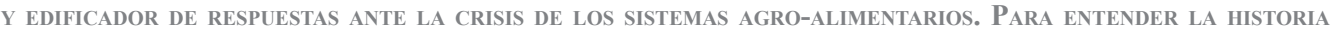
DE ESTE PROCESO HAY QUE REMONTARSE A LOS COMPLEJOS SISTEMAS AGRÍCOLAS TRADICIONALES, CONSIDERADOS

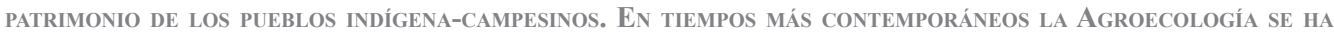
NUTRIDO DEL APORTE DE ACTORES SOCIALES QUE ENFRENTÁNDOSE AL PARADIGMA DESARROLLISTA Y A LA TECNOCRACIA EMPRESARIAL MODERNIZANTE, LOGRARON IMPULSAR EL MOVIMIENTO. LOS ACTUALES DESAFÍOS SE RELACIONAN A LA COMPLEJA REALIDAD DEL MUNDO RURAL, -CADA VEZ MÁS EMPOBRECIDO Y DESARTICULADO-; DONDE SE REQUIERE DE UNA ALIANZA FRATERNA CAMPO-CIUDAD PARA DISEÑAR Y ACTIVAR NUEVAS ESTRATEGIAS PARA LA EXPANSIÓN Y RADICALIZACIÓN AGROECOLÓGICA QUE GARANTICE LA SOBERANía ALIMENTARIA DE LOS PUEBLOS.
\end{abstract}

Palabras Claves: historia de la agroecología - economía CAMPesina - Soberanía Alimentaria - economía SOLIDARIA

\section{Abstract}

Agro-ecology in Ecuador has become the motor of a Heterogenous and dynamic Social Movement GENERATING RESPONSES TO THE CRISIS IN AGRI-FOOD SYSTEMS. TO UNDERSTAND THE HISTORY OF THIS PROCESS, WE HAVE TO GO BACK TO COMPLEX TRADITIONAL AGRICULTURAL SYSTEMS, CONSIDERED THE HERITAGE OF INDIGENOUS AND CAMPESINO COMMUNITIES. AT PRESENT, AGRO-ECOLOGY BENEFITS FROM SOCIAL ACTORS WHO, FACED WITH A PARADIGM OF DEVELOPMENT AND A MODERNIZED BUSINESS TECHNOCRACY, STIMULATED THE CREATION OF THE MOVEMENT. CURRENT CHALLENGES RELATE TO COMPLEX REALITIES OF THE INCREASINGLY IMPOVERISHED AND DISJOINTED RURAL WORLD, WHERE A FRATERNAL URBAN-RURAL ALLIANCE IS NECESSARY IN ORDER TO DESIGN AND ACTIVATE NEW STRATEGIES FOR THE EXPANSION AND RADICALIZATION OF AGRO-ECOLOGY WHICH GUARANTEE COMMUNITIES' FOOD SOVEREIGNTY.

KeYwords: AgroecologY HISTORY - CAMPESINA ECONOMY - FOOD SOVEREIGNTY - SOLIDARITY ECONOMY.

* Agrónomo, especializado en Agroecología y Soberanía Alimentaria. Ex - representante nacional del movimiento agroecológico y de las asociaciones de consumidores ante la COPISA - Conferencia Plurinacional e Intercultural de Soberanía Alimentaria. 


\section{Introducción}

$\mathrm{E}$ 1 presente artículo tiene como objetivo caracterizar al movimiento social ecuatoriano que se articula alrededor de la agroecología; trataremos de describir el proceso histórico en el que se construye este modelo agrario que, más allá de entenderse como disciplina científica o sistema de tecnologías, es percibido por las miles de familias que la practican como una opción de vida que hace posible y tangible su liberación de las estructuras económicas, tecnológicas e ideológicas que las dominan.

Vista de ese modo la agroecología se constituye en vía práctica y política para la recuperación de la Soberanía Alimentaria de los pueblos, es ahora un nuevo componente de las demandas históricas del movimiento indígena campesino ecuatoriano, quienes por décadas reclaman por una reforma agraria integral, por una distribución justa y equitativa de los recursos productivos como agua y tierra, o por una participación real en la toma de decisiones que afectan a la sociedad rural, para así alcanzar el derecho al buen vivir - sumak kawsay.

En el Ecuador, la Agroecología asume características propias: Se ha constituido en la ventana que enlaza campo y ciudad en defensa del buen alimento; es decir, ha dejado de ser una dinámica puramente rural o campesina, y se ha consolidado como un puente de relación intercultural urbano-rural donde actores sociales vinculados a la salud, nutrición, gastronomía, ecología, jóvenes e incluso artistas, han encontrado en la Agroecología un modo de acción colectiva y constructiva de nuevos escenarios de cambio social; por otra parte, ha cobrado relevancia política al incorporarse, por vez primera, en las principales normativas nacionales, particularmente en la Constitución de la República'1 y en la Ley Orgánica del Régimen de Soberanía Alimentaria². Estos y otros avances jurídicos denotan una capacidad de movilización e incidencia de actores sociales que apuestan conscientemente por un cambio social e institucional en el Estado ecuatoriano.

\section{Agroecología: un concepto dinámico}

Queda dicho que la agroecología se comprende como un modelo agrario integral constituido no solo por dimensiones científicas y tecnológicas, sino también sociales, ambientales y políticas. Este nuevo, pero a la vez antiguo modelo, se inspira en los ciclos y procesos de los ecosistemas naturales, en la agrobiodiversidad local y el conocimiento que sobre ella han desarrollado las diversas comunidades agro-alimentarias y en las ingeniosas tecnologías apropiadas que han generado, siempre en dialogo con conocimientos proveídos por las ciencias modernas. Es así como se logran sistemas agroalimentarios sostenibles, productivos, libres de agrotóxicos y otros contaminantes.

\section{Agriculturas rebeldes ${ }^{3}$}

Existen diversos entendidos y términos asociados al paradigma agroecológico que a menudo confunden y contradicen el sentido de su propósito; otros reducen o idealizan sus alcances; pero mejor aún, diríamos que muchos lo enriquecen desde múltiples visones. Por ejemplo, consideremos los modelos alternativos a la forma dominante y actualmente hegemónica que ejerce la agricultura moderna industrial ${ }^{4}$. Algunas de esas denominaciones, a pesar de tener diversos orígenes, muchas veces se usan indistintamente o como sinónimos; tales casos son las agriculturas: Orgánica, biológica, natural, ecológica, permacultura y biodinámica, entre las más reconocidas y difundidas.

\footnotetext{
Constitución de la República del Ecuador: Art.281 - numeral 3.

2 Ley Orgánica del Régimen de Soberanía Alimentaria - LORSA: Art. 14.

3 Referencia usada por Eduardo Ehlers (2001).

4 También conocida como revolución verde.
} 
Estas agriculturas representan diversas tendencias que aparecen desde la década de los años 20, 30 y 40 del siglo pasado en Europa, Norte América, Japón y Oceanía, nutridas por los conocimientos milenarios de agriculturas ancestrales en diversas regiones del mundo y que en definitiva ofrecen una respuesta a la imposición y expansión de la revolución verde y su visión reduccionista del complejo agrario. Ellas han influido notablemente en la comprensión de los sistemas agrícolas, y tienen rasgos comunes; por ejemplo, se oponen en principio a la artificialización extrema de la producción agrícola, al uso de agrotóxicos, a la mecanización inapropiada y a estructuras de monocultivo insostenibles; así mismo, proponen estimular la fertilidad natural de los suelos, su biodinámica y la agrobiodiversidad local, entre otras características.

\section{Modelo de sustitución de insumos y agricultura limpia}

A menudo se observa una simplificación de estos enfoques cuando se propone solamente la sustitución de insumos químicos tóxicos por otros de menor impacto ambiental, y se limita el objetivo de la producción agrícola al provecho de nichos de mercado especializados en alimentos sin pesticidas ${ }^{5}$. A esta modalidad muchos asumen en llamarla agricultura orgánica, aunque pueda guardar distancia con el paradigma agroecológico y las diversas corrientes de agriculturas rebeldes, pues no considera otras variables de la estructura agraria, ni los principios de la soberanía alimentaria y la economía solidaria, ni el papel crucial de la agricultura campesina, o la responsabilidad y actoría social del consumidor ante los sistemas agroalimentarios.

Algo similar ocurre con la denominada agricultura limpia que por lo general implica un uso reducido de insumos de síntesis química, y en ocasiones también se trata de una mezcla de químicos y orgánicos. Muchos agricultores practican esta modalidad como efecto de su propia racionalidad económica, pues la consideran como una estrategia de reducción de costos de producción, en vista de los cada vez más altos precios de fertilizantes y pesticidas ${ }^{6}$.

Concluimos entonces que las diversas tendencias de agriculturas alternativas han surgido de múltiples raíces y que han constituido aportes al desarrollo de tecnologías, modelos adaptativos y formas de producción sostenibles; en ocasiones han sido cooptadas por el mismo modelo dominante y las industrias de gran capital, sin embargo guardan todas ellas sinergias, similitudes indiscutibles y siguen siendo fuente de apreciación del conocimiento sobre los sistemas agrarios y las formas apropiadas de tratar con ellos.

\section{Agroecología: un enfoque integral}

Ahora bien, la agroecología se consolida como modelo productivo y como evolución de las ciencias agrarias a partir de la década de 1980 en América Latina, toma como base la enorme riqueza de la agricultura ancestral y los nuevos conocimientos sobre el funcionamiento de los ecosistemas naturales; integra diversas disciplinas científicas tanto ambientales, como agronómicas y sociales. A diferencia de la agronomía convencional, la agroecología aplica la teoría de sistemas complejos para poder diseñar y establecer agroecosistemas de manera sostenible, superando así la lógica positivista y fragmentada que propone la antigua escuela quimista7. Es impulsada por investigadores y comunidades campesinas, quienes codo a codo trabajan ardua y rigurosamente para alcanzar una propuesta de desarrollo apropiada, y que logra sinergias entre saberes tradicionales y conocimientos modernos.

5 Estos mercados a menudo se consideran elitistas y muchas veces excluyentes.

6 Particularmente aquellos que usan materia prima de origen fósil.

7 Nos referimos a las orientaciones de Justus Von Liebig, quien a mediados del siglo XIX sentó las bases para el uso de minerales de síntesis química en la agricultura y se considera el padre de la "revolución verde". Siguiendo el paradigma industrial mecanisista, el modelo se orienta a la especialización, homogeneización, y en general al análisis no sistémico del problema agrario. 
Esto implica un salto metodológico puesto que la Agroecología se construye por procesos de investigación e innovación participativa, rompiendo con las fórmulas convencionales que siempre optaron por la transferencia tecnológica, según la cual el conocimiento científico parte desde los centros académicos hacia los márgenes "vacíos de tecnología" en las comunidades campesinas. En contraste se proponen modelos de educación popular ${ }^{8}$, la lógica de campesino a campesino ${ }^{9}$, y el diálogo de saberes ${ }^{10}$. Esta nueva visión permite, como veremos más adelante, que la Agroecología paulatinamente se vaya integrando en el pensar y el quehacer de diversas fuerzas sociales, movimientos campesinos, organizaciones de desarrollo y centros de conocimiento, hasta alcanzar la dimensión contemporánea de ciencia, opción de vida y vía política.

\section{Definiciones}

En el Ecuador se reconocen varias definiciones de Agroecología propuestas por organizaciones campesinas, redes agroecológicas, organismos no gubernamentales o centros académicos ${ }^{11}$. Aquí únicamente presentamos una elaboración colectiva que se puede apreciar en el proyecto de Ley de Agrobiodiversidad y Fomento Agroecológico presentado por diversas organizaciones sociales a la Asamblea Nacional Legislativa en el año 2012, trabajo en el que participaron más de 2500 personas, la mayoría de ellas mujeres y hombres del campo dedicados a la producción agroecológica $^{12}$ :

"Es la forma de agricultura basada en una relación armónica y respetuosa entre seres humanos y naturaleza. Integra dimensiones agronómicas, ambientales, económicas, políticas, culturales y sociales; genera y dinamiza permanentemente el diálogo entre las sabidurías ancestrales milenarias y disciplinas científicas modernas. Se inspira en las funciones y ciclos de la naturaleza para el desarrollo de sistemas de producción, distribución y consumo agrícolas sostenibles, eficientes, libres de agrotóxicos, transgénicos y otros contaminantes. Los modelos agroecológicos incluyen aquellos sistemas ancestrales tales como: Ajas, chakras, eras, huertas y otras modalidades de fincas y granjas integrales diversificadas".

En el mismo documento se proponen los siguientes objetivos de la producción agroecológica:

1. Garantizar la fertilidad y biodinámica natural del suelo;

2. Promover la recuperación y conservación de la agrobiodiversidad;

3. Promover el manejo adecuado de cuencas hidrográficas para garantizar la sostenibilidad de los sistemas agrícolas y ecosistemas en general.

4. El aprovechamiento adecuado del agua y mantenimiento de sus fuentes;

5. La optimización de ciclos naturales de nutrientes y energía;

6. Incrementar la inmunidad natural de los sistemas agrícolas;

7. Recuperar el equilibrio y capacidad regenerativa de los sistemas agrícolas, liberándolos del uso de pesticidas, agrotóxicos y transgénicos.

8. Incrementar y optimizar la productividad agrícola de forma sostenible y permanente.

9. Garantizar la economía familiar campesina y el consumo saludable de alimentos culturalmente apropiados.

10. Recuperar el talento, protagonismo y centralidad de la familia campesina en el desarrollo de los sistemas agrarios y alimentarios.

8 Hablamos de la opción política educativa impulsada por Paulo Freire y muchos otros educadores latinoamericanos.

9 El modelo de construcción horizontal del conocimiento originado en Centroamérica en los años 70 y adoptado por los movimientos campesinos e indígenas en el continente.

10 El reconocimiento mutuo entre el saber ancestral y los aportes de la ciencia moderna.

11 Algunos de ellos se pueden leer en "La Agroecología está presente", Publicación de Heifer Ecuador, 2015.

12 Proyecto impulsado por la Conferencia Plurinacional e Intercultural de Soberanía Alimentaria (COPISA) entre los años 2009 y 2012 por mandato de la Ley de Soberanía Alimentaria. El proyecto avanzó a primer debate en la ANL y aún se espera su continuidad. 
Una versión similar a este concepto se encuentra publicada en la nueva Normativa general para la promoción y regulación de la producción orgánica, biológica, ecológica en el Ecuador, vigente desde el año $2013^{13}$. En este caso se considera a los sistemas de producción Agroecológicos como un modelo diferente a otras denominaciones (orgánica, biológica, ecológica), y se lo libera de las normas de regulación y fórmulas de certificación de tercera parte, reconociéndose en su lugar a los sistemas participativos de garantía local (spg), que son de uso regular entre las organizaciones campesinas y redes agroecológicas como instrumentos de fomento, promoción y garantía:

\begin{abstract}
"Modo de producción agrícola que se inspira en el funcionamiento y ciclos de la naturaleza, así como en el diálogo entre los saberes ancestrales y los conocimientos modernos, para el diseño y manejo sustentable de agroecosistemas, liberándolos del uso del uso de agrotóxicos, OGM, y otros contaminantes. Promueve la agrobiodiversidad, la integración de cultivos, crianzas animales, forestales y el manejo ecológico de suelo, agua y recursos productivos; se orienta preferentemente a la agricultura familiar campesina y la consecución de la soberanía alimentaria, e incluye sistemas ancestrales de producción como Ajas, Chakras, Eras, Huertas y otras modalidades de fincas agroecológicas diversificadas".
\end{abstract}

\title{
El origen de la agroecología ecuatoriana
}

\section{Agricultura ancestral y patrimonial: respuestas del pasado para la agricultura del futuro ${ }^{14}$}

Si hemos de preguntarnos sobre el origen de la agroecología en el Ecuador habrá que remontarse a una fuente segura de conocimiento y por supuesto la encontramos en los importantes sistemas agrícolas ancestrales y patrimoniales que en buena parte se encuentran todavía vigentes; aquí una breve reseña de algunos de los más reconocibles, sus rasgos y aportes tecnológicos.

\section{La chakra andina}

La chakra ${ }^{15}$ andina es la forma de agricultura propia de los pueblos indígenas quichuas de la sierra y podemos encontrarla en todo el callejón interandino, propiamente desde el sur de la provincia de Carchi (fronteriza con Colombia) hasta el norte de Loja ${ }^{16}$ (fronteriza con Perú). Se caracteriza por una alta agrobiodiversidad y un complejo sistema de semillas y adaptaciones varietales que se desarrollan en los diversos pisos agro-climáticos de la serranía, aproximadamente entre los 2400 y 3500 m.s.n.m., donde se reconocen generalmente tres zonas: alta, media y baja (y zonas de transición). Desde su origen prehispánico, la chakra se orienta a la satisfacción de la alimentación familiar y comunitaria, este criterio es el que determina qué y cuánto debe sembrarse. La influencia del ciclo lunar y varias señas agroclimáticas, definen cuándo sembrar; los solsticios y equinoccios marcan los hitos del calendario agrofestivo andino. Una serie de prácticas ingeniosas y tecnologías muy funcionales para el manejo ecológico del suelo, agua, cultivos y crianzas, son las claves para la sostenibilidad del agroecosistema y explican cómo producir.

Otra característica clave es el complejo cultural, los ritos y tradiciones ancestrales que acompañan el desarrollo de cultivos, crianzas y alimentación; éstos le dan sentido espiritual y de profunda conexión con la realidad Allpa Mama (madre tierra-suelo vivo), Yaku Mama (agua

13 La normativa se puede revisar en www.agrocalidad.gob.ec, y una norma específica para el reconocimiento de los SPG agroecológicos se encuentra actualmente en discusión.

14 Texto adaptado de SIPAN - Sistemas Ingeniosos de Patrimonio Agrícola, publicado por la FAO y Ministerio de Cultura y Patrimonio del Ecuador - autor: Roberto Gortaire A. (2014 - 2015).

15 Comúnmente se pronuncia "Chagra".

16 Sin embargo, se ha podido constatar que muchos principios y tecnologías, incluso el sentido y la cultura de los indígenas quichua andinos y su chakra, se han expandido e influyen en las agriculturas de otras regiones, desde los pueblos pastos en el norte, paltas en el sur, hasta la amazonía y costa. 
viva) y la Pacha Mama $^{17}$ (el contexto natural y energía vital universal), y han sido claves en el mantenimiento de la cohesión y ampliación del tejido social, que se expresa en la familia, la comunidad indígena y sus formas organizativas.

\section{El wachu rozado y la finca de los pastos}

El wachu rozado es una tecnología de labranza mínima de origen milenario, base de un complejo agrosilvo pastoril que denominaremos "Finca de los Pastos", haciendo referencia a los pueblos ancestrales que habitaron los territorios norandinos del Ecuador y sur de Colombia, particularmente la provincia del Carchi, y que hoy se reconocen en proceso de revitalización cultural. El sistema integra una mezcla de pastizales (que incluye variedades silvestres y modernas) para la crianza de ganado vacuno en rotación con variedades de papas, y pocas veces otros tubérculos y cultivos andinos; además plantas forestales y arbustivas con funciones ecológicas, mecánicas o medicinales. La práctica del wachu rozado se aplica de forma manual con un apero específico (palón con cute $^{18}$ ). La finca de los pastos se desarrolla en el contexto del Páramo Norte Andino donde el conocimiento profundo y la relación viva y cercana con este ecosistema frío y húmedo, es otra característica importante de la cultura agrícola que aquí se construye.

\section{Siembra de agua y huertas paltas}

Hablamos primero del sistema de siembra de agua o Catacocha, que es un humedal léntico artificial de gran complejidad tecnológica de origen ancestral propio de la región de los Andes Bajos Ecuatoriales ${ }^{19}$, territorio que en el período de integración $(900$ a 1470 DC) fue ocupado por los denominados Paltas y otras importantes culturas, previo la incursión del incario. Ellos fueron capaces de adaptar su modelo agrario al ecosistema de bosque seco y la heterogeneidad edafo-climática de la zona. La Catacoch ${ }^{20}$ implica la creación de grandes lagunas de infiltración en zonas altas estratégicamente dispuestas, que captan la escorrentía de aguas lluvias a través de brazos o canales y la percolan a la profundidad del suelo. Esta agua infiltrada aparece en vertientes en zonas más bajas y se moviliza por quebradas; allí se instalan los denominados "tajamares", que son barreras o muros de piedra interpuestos en el curso de la quebrada que reducen la velocidad del agua y la represan evitando su pérdida, mientras que en sus riberas permiten la generación de biomas con alta diversidad. Ya en el ingreso a los predios se disponen los "pilancones" que son reservorios o estanques que permiten la captación del agua para el uso agrícola y consumo humano. Se ha observado que durante los inviernos el sistema se llena (saturación del subsuelo por la infiltración), que luego es aprovechado en los meses muy secos (aumenta el volumen en las vertientes).

Los sistemas agrícolas que se sirven de las catacochas tienen gran notoriedad paisajística, agrobiodiversidad y un complejo tecnológico basado en sistemas agroforestales que denominaremos "Huertas de los Paltas" por su autenticidad y particularidad. La crianza de animales no deja de ser importante y es sorprendente también el sistema tradicional de maíz de una variedad criolla adaptada a las condiciones de sequedad y terrenos pedregosos (maíz de piedra); el sistema tradicional de maíz incluye al ataco y al sangorache, otras especies igualmente

17 Muchas veces también se refiere al suelo vivo como Pacha Mama.

18 Se refiere a un tipo de azadón modificado con un manubrio de madera diseñado para tener mayor resistencia (cute) para la tarea de rompe y volteo de la champa o adobe (porción de tierra y pasto).

19 Se ubica en la transición entre los andes septentrionales y andes centrales, desde el Nudo del Azuay - Ecuador hasta Cajamarca - Perú, ocupando la provincia de Loja parte de El Oro y Zamora Chinchipe, aunque particularmente nos referiremos al cantón Paltas y su cabecera Catacocha.

20 Su apariencia pantanosa da sentido a la denominación de Cata-cocha (en quichua: khata = cobija o manto / cocha = lago o laguna); sin embargo lo más probable es que el prefijo Cata sea un enfático para caracterizar el tamaño del lago $($ Cata $=$ gran o grande $)$. 
resistentes a la sequía. En las zonas más bajas, donde no operaba el sistema de lagunas de infiltración, se idearon las "terrazas hundidas" que permiten la saturación de humedad durante el invierno para sobre ellas cultivar en verano; también se practica la agricultura de "lecho de río" que dispone del propio canal del río en el verano cuando baja o cesa el caudal, y así se habilitan huertas que garantizan la producción alimentaria.

\section{La finca montubia}

Denominaremos finca montubia al sistema agrícola diversificado que tiene lugar en las provincias costeras ecuatorianas y es practicado por familias campesinas de tradición montubia ${ }^{21}$. El sistema puede centrarse en el desarrollo de cultivos como cacao, café o banano, sin embargo integra cultivos frutales, forestales, hortalizas y crianzas de animales, y muchas veces se asimila con el bosque tropical. En la finca suelen coexistir tres subsistemas: las albarradas; la finca propiamente dicha; y las eras o huertas.

Las albarradas consisten en un humedal artificial, tecnología de origen ancestral que es el centro de un sistema complejo de manejo de recursos hídricos: se capta agua por métodos de infiltración en épocas de invierno, se destina para riego, la crianza de peces, patos y se convierte en sitio de refresco y recreación. Es común en zonas secas y hace posible el regadío de la finca donde la diversificación, cobertura y manejo orgánico del suelo, reducen la demanda hídrica y así se integra un círculo virtuoso en el aprovechamiento del agua.

En la finca propiamente dicha se desarrollan principalmente frutales y cultivos muy diversos y propios del trópico tales como banano, cacao, yuca, variedades de arroz y muchos más. En un área menor se disponen las denominadas Eras o huertas: se trata de la despensa familiar de hortalizas, legumbres, condimento, frutales y otros cultivos propios de la alimentación básica familiar.

\section{Canoeros, colinos y canteros}

En el norte de la provincia de Esmeraldas se encuentra ríos como el Cayapas y Santiago en cuyas riberas conviven, desde tiempos ancestrales, comunidades de diverso origen cultural mayoritariamente de nacionalidad Chachi y Afrodescendientes. Coexisten en un ecosistema de singular belleza paisajística donde se combina el río con el bosque húmedo tropical. Han desarrollado relaciones interculturales estables, y diversas adaptaciones y sinergias con su entorno. Incluyen básicamente tres subsistemas agrícolas: canoeras, colinos y canteros. Las canoeras son pequeños huertos hortícolas y medicinales que se cultivan en camas elevadas construidas generalmente con madera y caña guadua, pero también es común el uso de viejas canoas de río que de este modo se reciclan para disponer el huerto, de ahí la denominación de cano-era.

Los colinos o $P$ 'atavitia en el idioma de los chachis (cha'apalachi), son modelos de agricultura ancestral de roza y tumba que pueden explicarse como fincas familiares diversificadas que se desarrollan en armonía con el bosque húmedo tropical en extensiones que generalmente van de media a una hectárea. Sus cultivos principales son banano, yuca, coco, cacao, chonta y diversos frutales. En la primera fase de siembras se incluyen asocios de maíz (variedades llamadas canguil y criollo), con fréjol, haba, cucurbitáceas y otras plantas. La denominación "colino" tiene otro uso común y se refiere a la forma botánica de reproducción de plantas como el plátano. El término se usa indistintamente para referirse a la finca propiamente dicha y a cualquier ramilla o brote apropiado para siembra.

21 Antigua denominación cultural que expresa un mestizaje entre pueblos originarios de las zonas costaneras ecuatorianas, pueblos afrodescendientes y migraciones de otras regiones. Montubio = el que viene del monte. 
Cantero o E'vitia para los chachis, es el nombre que se da a un cultivo de caña, producto que ganó importancia en la región por diversos usos y procesos que se le generan (miel de caña, panela, guarapo, aguardiente, bagazo, etc.). Se observa generalmente en parcelas de entre 500 o 1000 metros cuadrados encerradas entre árboles y arbustos propios de la diversidad del bosque tropical. La dinámica fluvial determina los procesos de fertilidad natural de los suelos de las riberas, que es donde se cultivan los colinos y canteros; y el arrastre del río que trae suelo y hojarasca desde tierras altas forma un compuesto orgánico denominado marmaja, que es el sustrato más apropiado para el cultivo de las canoeras.

\section{Pueblos del manglar}

Los pueblos ancestrales del ecosistema manglar en Ecuador se denominan así puesto que consideran que la base de su identidad cultural, de su racionalidad social y económica está vinculada trascendentalmente con él. Ocupan las zonas costaneras de franja marina y estuarios de ríos. Principalmente lo componen afroecuatorianos, mulatos y campesinos de identidad montubia. En el manglar coexisten al menos dos actividades fundamentales como la recolección de concha y pesca artesanal de especies del estuario del río; sin embargo estos pueblos no conviven únicamente en la franja de manglar, sino con otros subsistemas: la zona de transición o raconchal, vegetación donde se desarrolla y captura el cangrejo; la finca diversificada (similar a la descrita para los pueblos montubios) y el bosque húmedo tropical. Es decir que los pueblos del manglar se construyen en una "sociedad" entre estos cinco subsistemas, constituyendo un complejo agroalimentario y recolector en armonía con ecosistemas naturales.

\section{Aja shuar}

La Amazonía ecuatoriana, uno de los centros de biodiversidad más notables del mundo, también alberga a los que podrían considerarse los sistemas agrícolas más complejos, auténticos y diversificados que existen en el país. El Aja, practicado por la nacionalidad Shuar, está prácticamente "mimetizado" con el ecosistema natural. En él es determinante el rol de la mujer shuar ya que es casi exclusiva su responsabilidad en el manejo del sistema. Es de importancia crucial la práctica de diversos ritos como los Anent: plegarias o cantos de singular belleza que se realizan en diversos momentos y que son una muestra del respeto y profundo afecto que el pueblo Shuar dispensa a la naturaleza.

Los Nantar o talismanes son piedras especiales sigilosamente ocultas por la mujer en algún punto dentro del Aja y que acogen a Nunkui, la reina del $A j a$, quien emite la energía y vitalidad necesaria para el desarrollo de los cultivos. Los diversos arreglos y asocios entre cultivos son muy funcionales y complejos; existe un notable conocimiento sobre las razones y períodos de fuerza y fragilidad del suelo, característica dual muy propia de la amazonia, y se han creado tecnologías agrícolas adaptadas a esta condición; por ejemplo, la movilidad del Aja: hablamos de un área de 1 ha aproximadamente que se instala en un bosque socolado (roza, tumba y quema), en un período de cultivo que no va más allá de 3 o 4 años (aja vieja); luego viene un período de descanso funcional o regeneración de ecosistema natural que dura entre 5 y 15 años. El Aja se mueve a otro sitio reiniciando el ciclo con el corte por roza de hierbas y arbustos, luego se tumban los arboles más grandes. El proceso de descomposición y formación de suelos es dinámico y acelerado y a menudo se agregan las cenizas que se obtienen de las quemas de hierbas secas y árboles, lo cual mineraliza estos suelos orgánicos.

La agrobiodiversidad manejada en un Aja incluye más de 100 diversos cultivos, donde generalmente la yuca hace de guía o centro de proceso agroalimentario (más de 30 variedades reconocidas); papa china, pelmas, kenkes (tubérculos), piña, camote, porotos, plátanos, maní, maíz, frutales diversos, todos ellos cultivos imbricados en un conjunto multifuncional de especies. Para un observador ligero parecería una mezcla sin orden, sin embargo pueden 
reconocerse ciertos "secretos": hay especies que deben sembrarse junto a la yuca y otras que no deben estar en el Aja pues perjudican el engrose; unas prefieren la sombra y algunas la evitan, y así un sinnúmero de criterios agronómicos. Además se reconocen y cultivan decenas de plantas medicinales y es nada despreciable la diversidad de crianzas animales que incluyen sahino, pavos, guatusa, guanta. La conexión del Aja con la diversidad del bosque húmedo amazónico integra otra serie de frutos silvestres, animales, insectos, aves, y peces del río que enriquecen la dieta increíblemente diversa y saludable del pueblo Shuar.

\section{Chakra amazónica}

Expresión que usan los pueblos ancestrales quichuas del oriente ecuatoriano para denominar a sus sistema agrícola, el mismo que guarda similitudes con otras modalidades tradicionales en el territorio en términos de agrobiodiversidad y sistema de manejo, sin embargo hay matices y particularidades que le otorgan autenticidad y originalidad. El primer elemento determinante es la relación con el río, en este caso nos referiremos a una agricultura itinerante de lecho de río. Ocurre que en las crecientes y bajantes del río en el transcurso del tiempo, se van formando pequeños islotes que son áreas fertilizadas por el río, y por el contrario otras zonas son arrasadas por él.

Un enfoque central es el manejo del suelo, hay mayor atención a los ciclos de fertilidad en relación con el río en la "formación de suelo" a partir de la biomasa vegetal que por ciclos y aceleradamente se incorpora. Es importante el sistema tradicional del maíz variedad criolla, adaptado ancestralmente a las condiciones de extrema humedad y alta biodinámica, pero sin duda es la yuca nuevamente la planta madre que genera los ritmos en el sistema, se reconocen algunas variedades y como cosa particular en los períodos de cosecha se mantienen los sembríos de yuca totalmente "enmalezados", es decir se permite el desarrollo de vegetación adventicia en la base del cultivo, pues con esta técnica se garantiza la frescura del producto.

El siguiente cuadro muestra un resumen de los principales sistemas agrícolas que pueden considerarse patrimonio del Ecuador.

\section{CUADRO 1. Sistemas agrícolas Patrimoniales del ECUAdor}

\begin{tabular}{|c|l|l|}
\hline No. & Sistema Agrícola & Característica determinante \\
\hline 1 & Chakra andina & $\begin{array}{l}\text { Manejo y adaptación a diversos pisos climáticos / centro de origen de } \\
\text { cultivos y crianzas / sistema de semillas muy desarrollado. }\end{array}$ \\
\hline 2 & Finca pasto & $\begin{array}{l}\text { Rasgos ancestrales en tecnología de labranza mínima Wachu rozado/ } \\
\text { sistema silvopastoril/ conocimiento de ecosistema páramo. }\end{array}$ \\
\hline 3 & Huerta palta & $\begin{array}{l}\text { Adaptación al clima extremo de sequía / innovación tecnológica para } \\
\text { siembra de agua / sistema agroforestal estable. }\end{array}$ \\
\hline 4 & Aja shuar & $\begin{array}{l}\text { Agrobiodiversidad muy alta / mimetizado con selva amazónica / } \\
\text { profundidad espiritual en la relación con la naturaleza. }\end{array}$ \\
\hline 5 & Chakra amazónica & $\begin{array}{l}\text { Agricultura de lecho de río / comprensión de funcionamiento de ciclos de } \\
\text { fertilidad del suelo y dinámica del río. }\end{array}$ \\
\hline 6 & Finca montubia & $\begin{array}{l}\text { Adaptabilidad a ecosistemas secos y húmedos / alta agrobiodiversidad / } \\
\text { integración de subsistemas finca-era-albarrada. }\end{array}$ \\
\hline 7 & Pueblo de manglar & $\begin{array}{l}\text { manejo integrado de 5 ecosistemas donde desarrollan pesca de estuario, } \\
\text { recolección y agricultura: manglar-raconchal-finca-bosque húmedo tropical. }\end{array}$ \\
\hline 8 & Pueblos del Cayapas & $\begin{array}{l}\text { Manejo integrado de 3 subsistemas agrícolas (canoera, colino y } \\
\text { cantero), pesca en río, recolección y caza en bosque húmedo tropical / } \\
\text { interculturalidad Cachi - Afro. }\end{array}$ \\
\hline
\end{tabular}


Estos representan solo una muestra de los sistemas agrícolas de carácter ancestral en el Ecuador y son base de la actual agroecología ecuatoriana, y a pesar del impacto socio cultural y económico que viven las comunidades originarias por la expansión urbana, la agricultura industrial y el extractivismo, aún podemos reconocer el enorme aporte de sus conocimientos y saberes para construir nuevos modelos agrarios.

\section{Contexto histórico}

\section{¿Cómo llegó a desarrollarse el pensamiento agroecológico en el Ecuador?}

Hemos visto ya la caracterización de la agricultura ancestral ecuatoriana que claramente guarda los principios y raíces tecnológicas de la Agroecología, sin embargo para entender cómo se construyó el paradigma agroecológico en nuestro país, también debemos considerar la historia del movimiento indígena campesino a lo largo de sus luchas y procesos de resistencia, puesto que nuestra agroecología es una respuesta consecuente con esas reivindicaciones. Consideremos los períodos que construyeron esta realidad ${ }^{22}$ :

\section{Conquista, colonia y resistencia $(1526-1800)$}

Sabemos que el proceso de colonización española produjo una transformación radical en la sociedad y la cultura, por supuesto también en los sistemas agroalimentarios; el despojo, saqueo y explotación extrema están ampliamente documentados. La agricultura ancestral que describimos en el capítulo anterior apenas pudo resistir en relictos y en espacios limitados por la expansión de nuevas estructuras de control del territorio. Para Manuel Suquilanda “... la producción agrícola prehispánica no fue monocultivista, sino que se basó en arreglos tecnológicos diversificados que trataban en lo posible de imitar a la naturaleza, se idearon ingeniosos sistemas conservacionistas para evitar su deterioro" (entrevista personal, 2015). Ciertamente, antes de la conquista hasta el año 1540 se aprecia la influencia del incario en las formas de agricultura, como se puede inferir de la chakra andina, técnicas como el wachu rozado, diversas herramientas agrícolas, la construcción de camellones, andenes, terrazas y sistemas de riego que incluso hasta nuestros días siguen vigentes y tienen su origen en la cultura inca.

En esta etapa buena parte de la estructura laboral fue forzada a abandonar la agricultura para privilegiar la extracción minera, obrajes de textiles y otras actividades. Muchos dirán que este patrón político que desvaloriza la agricultura campesina persiste hasta nuestros días; y sin embargo del brutal cambio paradigmático que trae el proceso colonizador, existen notables ejemplos de resistencia indígena campesina que se presentan en diversos períodos de levantamientos y revueltas de aquellas sociedades.

\section{Independencia y república $(1800$ - 1872)}

En este período, la caída de los sistemas de explotación minera, textil y artesanal trae consigo la recuperación de la agricultura e inicia el sistema hacendatario, donde grandes propietarios de tierra aseguran la fuerza de trabajo indígena y campesina a través muchos sistemas de explotación. Esta modalidad va tomando mayor consistencia en la serranía ecuatoriana, mientras que en la costa se configura un modo agroexportador impulsado por el auge cacaotero y gracias a la relación de puerto de Guayaquil con los mercados internacionales. En contraste, la Amazonía se mira como territorio inhóspito, poco asequible, apenas útil por la posibilidad de explotación

22 Historia del Ecuador. 2003. GDDL. Grupo democracia y desarrollo local. Formación de liderazgos democráticos en Ecuador. 
maderera, y los pueblos que ahí habitan son considerados "salvajes" por tanto incapacitados de integrarse a la "civilización".

Grandes terratenientes acaparan enormes plantaciones con trabajo esclavo o explotación extrema; es notorio que la expansión de estructuras de monocultivo asociadas a la agroexportación estuvo más acentuada en la región litoral, mientras en la serranía se consolida la hacienda y sistemas precapitalistas como el concertaje (deudas artificiales creadas para exigir trabajo en pago), o el huasipungo (autorización de uso de pequeñas parcelas dentro de la gran hacienda a cambio de trabajo sin paga).

\section{El capitalismo agrario}

Es así que la naciente república ecuatoriana se funda en la explotación económica y social de las comunidades ancestrales. Hasta finales del 1890 no veremos cambios importantes en esta lógica, pero si grandes momentos de revueltas y levantamientos que fueron forjando la capacidad organizativa de estos pueblos; sus costumbres y saberes en la producción agrícola lograron persistir a pesar del despojo y sobre-explotación. Para el tiempo de la revolución liberal de Alfaro (1895) que fue acompañada y añorada por los movimientos campesino e indígena, ya la burguesía comercial agroexportadora era la principal y más dinámica fuerza económica del país, por ser proveedores del mercado mundial de café, cacao, cascarilla, tagua y madera. Se constituye una oligarquía que liga a la agroexportación costeña y a los terratenientes serranos, imbricados a su vez con la naciente burguesía comercial y financiera. Finalmente, estos sectores lograron apropiarse de ímpetu revolucionario e impidieron que se toque al poder feudal terrateniente y la lógica capitalista en haciendas y plantaciones, manteniendo intacto el control de la mano de obra. La resistencia indígena y campesina fue persistente y duramente aplastada en diversos episodios.

\section{Reformas y modernización agraria}

Ese modelo agroexportador primario fue motor del control capitalista sobre la economía y el poder político, el auge cacaotero primero y más tarde el denominado "boom bananero" son expresiones de esta realidad donde ya se pueden reconocer los límites y contradicciones de las estructuras de monocultivo expansivo y el paquete tecnológico asociado. Su constante ciclo de auge y crisis se deben al recurrente aparecimiento de plagas y enfermedades que mermaron su expansión, como también a la caída de los precios internacionales en diferentes períodos, lo cual hizo evidente la vulnerabilidad y debilidad propios de este modelo productivo y su dependencia económica. El sistema hacendatario serrano por lo general mantuvo su mirada en el mercado interno de alimentos, pero nunca impulsó la diversificación y mantuvo los sistemas de explotación sobre las poblaciones indígenas despojadas de sus territorios hasta ya bien entrado el siglo XX. La ineficiencia y pérdida de capacidad de acumulación de la hacienda, así como la resistencia y luchas de los movimientos sociales, fueron configurando una nueva etapa histórica de cambios.

La primera y segunda reformas agrarias que se impulsan entre los años 1950 y 1970, lograron modificaciones parciales en la estructura y tenencia de la tierra en muchas regiones del país ${ }^{23}$. Con grandes sacrificios y esfuerzos el movimiento indígena campesino, apoyado por sectores progresistas, logra la abolición de sistemas pre-capitalistas como el concertaje y el huasipungo, y en muchos territorios se logra la erradicación de la hacienda. La tierra de vuelta a manos de las comunidades implicó el despertar de su fuerza organizativa y el gran desafío de demostrar capacidad productiva.

23 Hay que reconocer que en la actualidad la concentración de la tierra en el Ecuador sigue aún en niveles importantes, según el último censo agrícola (2000) $6,41 \%$ de propietarios controlan $60,72 \%$ de la tierra cultivable. 
Instituciones del Estado y organizaciones no gubernamentales impulsan un esquema de "modernización agraria" que reniega de los sistemas agrícolas tradicionales y sugiere que los nuevos territorios bajo control indígena y campesino se integren a las estructuras de mercado, apliquen las mejores tecnologías disponibles para alcanzar mayor eficiencia y productividad, a saber: mecanización, monocultivo, semillas "mejoradas", uso de fertilizantes de síntesis química y agrotóxicos. Adicionalmente y tal como lo comenta Luis Macas ${ }^{24}$ “...la llegada de distintos paquetes tecnológicos, no siempre tenía la finalidad de mejorar la calidad y la productividad en el campo, sino que a veces primaban fines eminentemente comerciales".

\title{
Voces contra hegemónicas y construcción del pensamiento agrario alternativo
}

A finales de la década de 1970 aparecieron voces y expresiones que ya alertaban los posibles impactos de la "modernización agraria". F. Gangotena ${ }^{25}$ lo relata de esta manera:

\begin{abstract}
“en los años 60, poco antes de la primera reforma agraria, en sitios como Guamote ${ }^{26}$ el huasipungo se podía considerar como estrategia de resistencia ante la explotación hacendataria; en este pequeño lote existía gran diversidad agroalimentaria, se utilizaba majada de animales para la siembra y otras técnicas tradicionales; la familia indígena no manejaba dinero pues no recibía paga por su trabajo y estaba muy escasamente presente en los mercados, así que para satisfacer necesidades y enriquecer su diversidad se desarrollaban formas de reciprocidad entre comunidades e intercambios entre diversos pisos climáticos."
\end{abstract}

Para la segunda reforma, a mediados de los 70 y hasta inicios de los 80 , ocurre el cambio en tenencia de la tierra. Siempre se consideró un triunfo de la lucha social el fin de la hacienda y seguramente así es, pero hay que considerar que según muchos estudios la hacienda ya no era rentable (en la zona descrita 9 de cada 10 grandes haciendas estaban colapsando). El Estado expropio (a veces a precios exorbitantes) haciendas que a su vez fueron adquiridas con endeudamiento por parte de comunidades indígenas; por ejemplo un gran hacendado obtuvo 4 millones de sucres ${ }^{27}$ por la expropiación de 13 mil ha., con esto adquirió propiedades en la ciudad capital, mientras que las comunidades beneficiarias obtuvieron la tierra asumiendo una deuda importante. ¿cómo enfrentar esto cuando no se conocía el dinero y las comunidades estaban desarticuladas de los mercados? Había que pagar la deuda y demostrar productividad. El primer paso fue vender los animales ${ }^{28}$ con lo que se limitó el modelo tradicional de fertilidad de suelos, había también que enfrentar la producción pero ahora en mayor escala. Instituciones del Estado y ONG's promovieron estructuras de monocultivo y uso de semillas de mayor rendimiento, mecanización, uso de químicos, y demás tecnología de la revolución verde. Los efectos aparecieron a los pocos años enfrentándose una importante reducción de la agrobiodiversidad local; se incrementó la erosión y consecuente pérdida de fertilidad natural de los suelos; aumenta la presencia de plagas y enfermedades, entre otras consecuencias; sin mencionar los graves problemas de salud asociados al uso de agrotóxicos.

La primera voz que Gangotena recuerda alertar sobre este nuevo fenómeno fue ni más ni menos que a Monseñor Leonidas Proaño ${ }^{29}$ a quien en una reunión en Santa Cruz de Riobamba,

24 Líder histórico del movimiento indígena ecuatoriano - Ex presidente de la CONAIE (Confederación de Nacionalidades Indígenas del Ecuador) - Tomado del texto: Agroecología una apuesta necesaria - Foro Agroecología y Soberanía Alimentaria - Heifer - mayo 2004.

25 Francisco "Pacho" Gangotena: antropólogo y agricultor orgánico quien en 1982 junto a su familia creó la finca agroecológica Chaupi Molino en las cercanías de Quito que ha sido visitada por más de 30 mil campesinos y profesionales. Ex director de swissaid ecuador - entrevista personal 2015.

26 Cantón indígena de la provincia de Chimborazo en la serranía andina.

27 A valor actual probablemente más de 10 millones de dólares.

28 Ovejas y Vacunos principalmente; se calcula que en pueblos como Guamote se vendió más del 75\% de animales para afrontar deudas de tierra.

29 "El obispo de los indios" como se lo recuerda, trabajó en la diócesis católica de Riobamba y Guaranda desde los años 1950 hasta inicios de los 80 , siendo un valiente inspirador y animador del movimiento social a través de una teología de liberación. 
escucha decir: “Los químicos son las garras de imperialismo”. Muy pocos prestarían atención a tales comentarios en una época en la que se consideraba urgente y obvia la aplicación del modelo de agricultura industrial.

Fernando Larrea ${ }^{30}$ indica que, si bien en los primeros años si se evidenció un incremento de los rendimientos (caso típico en el inicio de los sistemas de monocultivo industrial), esto no significó un mejoramiento de la economía campesina; había más recursos en dinero en forma de créditos y y subvenciones de ONG's para integrar a los campesinos a la modernización, pero esto no traía los beneficios esperados, porque el mercado continuaba (como hasta hoy) controlado por otras fuerzas que expolian el trabajo campesino y no lo remuneran con justicia. En pocas palabras: las comunidades campesinas producían más, pero de un solo producto (vulnerabilidad) que no generaba la utilidad económica esperada, y se incrementaron los gastos en insumos, semilla, maquinaria y pago de deuda. En muchos casos este fue el origen del fenómeno de migración a las ciudades en busca de ingresos monetarios. Además, Luis Macas recalca que,

“...hay una contraposición entre la lógica de la acumulación del gran capital y del mercado, frente a una producción comunitaria. Aunque ya están dentro de la lógica del mercado, las comunidades indígenas no siempre logran entender la filosofía de su funcionamiento, y por eso las tildan de atrasadas; en nuestras comunidades mucha producción del año va destinada a redistribución, a las grandes fiestas, a la reserva de alimentos, a la reciprocidad". (Heifer, 2004)

Pero, tal como lo señala Pedro de la Cruz"1, "en medio de este complejo cambio social siempre encontramos casos donde no hubo una asimilación de la "revolución verde", puesto que muchas familias campesinas practicaron una estrategia doble (contradiciendo las orientaciones de técnicos y profesionales): por un lado se aceptaba la tecnificación moderna en monocultivo para enfrentar la demanda del mercado, y por otro se mantenía espacios de producción diversificada principalmente para el auto consumo; una inteligente fórmula que reduce los riesgos y multiplica las posibilidades de subsistencia. Comunidades enteras se vieron nuevamente frustradas y palparon el fracaso del sistema modernizante, así evidenciaron que las formas tradicionales de producción y su agrobiodiversidad tenían validez. Los sectores académicos y profesionales progresistas se implicaron en nuevos debates sobre el modelo agrario, más allá de la redistribución de la tierra. Este seguramente es el germen para la construcción de un pensamiento agrario alternativo que más tarde dará lugar al paradigma Agroecológico".

\section{Fases en la construcción de la agroecología ecuatoriana}

A continuación ensayamos una cronología en la construcción contemporánea del movimiento agroecológico ecuatoriano:

\section{Primer momento: constitución, debate de principios y orientaciones fundamentales (1980-1990)}

Como lo relata Suquilanda (2015),

“...en la década de los años 80, varios profesionales (agrónomos, sociólogos, biólogos, antropólogos) agrupados en organismos no gubernamentales, conjuntamente con organizaciones campesinas e indígenas, empezamos a cuestionar las tecnologías generadas en el INIAP y replicadas por las universidades, cuyos planteamientos no servían a los pequeños y medianos productores del país, pues demandaban suelos de gran extensión y buena calidad, planos, servidos con riego

30 Fernando Larrea, reconocido antropólogo y acompañante de las organizaciones campesinas ecuatorianas, ex director de Heifer Ecuador.

31 Dirigente indígena campesino de Cotacachi - Imbabura, ex presidente de UNORCAC y FENOCIN, ex asambleísta y actualmente Parmalentario Andino - entrevista personal 2015. 
y además de recursos económicos para invertir en maquinarias, semillas de alto rendimiento y agroquímicos; justamente, criterios que muy pocas veces corresponden a la realidad campesina. Otro cuestionamiento fue al uso de agrotóxicos de alto peligro (organoclorados, organofosforados y los hormonales/herbicidas) que antes habían sido utilizados como elementos de guerra (agente naranja y agente blanco). En el INIAP como en las universidades se sostenía que las técnicas ancestrales son obsoletas y que deben ser erradicadas para dar paso a las técnicas modernas que vienen desde los centros hegemónicos del poder mundial. Para esto actúan en el país técnicos ecuatorianos que habían sido llevados a Estados Unidos y México por las Fundaciones Ford y Rockefeller para ser entrenados en la aplicación de los paquetes tecnológicos de la Agricultura Convencional" (entrevista personal, 2015).

Entrada esta década ya se vive un proceso de expansión de modelos de agricultura industrial, lo cual acrecentaba las contradicciones y hacía urgente la proposición de alternativas concretas y viables. Veremos entonces una primera generación del discurso y puesta en práctica de la propuesta agroecológica (generalmente de otras denominaciones de agriculturas alternativas) impulsada básicamente por profesionales, personas entusiastas y pocas organizaciones no gubernamentales, siempre en diálogo con los movimientos indígena y campesino.

\section{Algunos actores claves}

En esos primeros años algunos investigadores e instituciones de desarrollo ya trabajan sobre la racionalidad de los sistemas agrícolas tradicionales, y proponen la regeneración de sistemas diversificados y la reintegración de animales y cultivos en finca (recuérdese que la visión convencional propone la fragmentación y especialización de los sistemas agrarios): Prácticas de conservación de suelos (Mag-Care-promusta, el Centro Andino de Tecnología Rural en Loja, Grupo Ecológico Camino Verde en Chimborazo, Brethren y Unida en Pichincha); uso adecuado de agua (Central ecuatoriana de servicios agrícolas - CESA, el consorcio CAMAREN, la Universidad de cuenca); reforestación nativa, alternativas de fertilización, recuperación de agrobiodiversidad y manejo de recursos fitogenéticos (importante trabajo del INIAP con la UCASAJ - organización indígena de Chimborazo); fincas integrales diversificadas (Fundación Ayuda en Acción - FEPP).

Los diferentes debates y procesos organizativos permiten definir los principios tecnológicos de la agroecología y se reconoce su integración con la agricultura ancestral. Se incorporan aquí los fundamentales aportes latinoamericanos donde se destaca la escuela chilena y peruana; por ejemplo se menciona recurrentemente al CLADES (Consorcio Latinoamericano de Agroecología y Desarrollo con sede en Lima), CET (Centro de Educación Tecnológica de Chile) y personalidades como Andrés Yuryevic, Toledo, Letelier; la escuela brasileña con Luxenberger, Pinheiro, Primavesi y otros como el colombiano Jairo Restrepo, llegaron al Ecuador y desarrollaron múltiples cursos y talleres. Los trabajos de gran rigor académico de Altieri y otros agroecólogos, que más tarde darán lugar a la SOCLA (Sociedad Científica Latinoamericana de Agroecología), son aportes insustituibles en la formación de los primeros técnicos y promotores campesinos.

Por su parte, las grandes organizaciones indígenas y campesinas bregaban por el reconocimiento de su identidad étnica, cultural y sus derechos políticos; en su relato ya incluían la necesidad de revitalización de sus formas tradicionales de producción y subsistencia; sin embargo están en un proceso de gran construcción y politización de su discurso histórico, y la agroecología no calza todavía en estas definiciones pues su énfasis aún está en lo tecnológico, pero si encuentra gran respuesta en organizaciones de base y de segundo grado (carácter provincial o regional) porque significa respuestas concretas a problemas cotidianos de la familia campesina.

Las primeras iniciativas de agriculturas alternativas vinieron muchas veces influenciadas por profesionales y cooperantes que traían consigo la versión de agricultura biológica europea, y la orgánica norteamericana. La primera asociación de productores biológicos PROBIO, creada 
a finales de los 80 por varios agricultores, entusiastas promotores de la agricultura orgánica - biológica, sigue esta corriente e incluso incorpora una primera idea de normas de garantía tomando la referencia europea y del IFOAM; muy reconocido en este momento el trabajo de Pacho Gangotena y su familia en la finca Chaupi Molino en las afueras de Quito. Fundación Brethren y Unida (FBU) y luego la Fundación Swissaid inician los primeros proyectos con orientación alternativa.

Situaciones similares ocurren en el austro ecuatoriano (provincia de Azuay) donde se despertaba ya gran dinámica por programas y proyectos de organismos no gubernamentales. En la sierra centro es referente el grupo ecológico "Camino Verde", las Escuelas Radiofónicas Populares (ERPE) con el apoyo de cooperantes internacionales inician procesos de capacitación, instalan la reconocida finca demostrativa de San Antonio, y una de las primeras tiendas de productos orgánicos del país.

En el siguiente cuadro mencionamos algunos actores sociales e hitos reconocibles que marcan esta etapa de primera constitución del proceso agroecológico en el Ecuador.

\begin{tabular}{|c|c|}
\hline \multicolumn{2}{|r|}{$\begin{array}{l}\text { CUADRO 2. ACTORES SOCIALES E HITOS RECONOCIBLES EN LA PRIMERA ETAPA DE CONSTITUCIÓN DE LA } \\
\text { AGROECOLOGÍA EN ECUADOR }\end{array}$} \\
\hline 1980 & $\begin{array}{l}\text { En la zona norte de Pichincha e Imbabura trabaja la Fundación Brethen Unida (FBU), de origen } \\
\text { alemán, que incursiona en la promoción de la agricultura biológica. }\end{array}$ \\
\hline \multirow{2}{*}{$\begin{array}{l}1980 \\
1986\end{array}$} & $\begin{array}{l}\text { CENTEP (centro de tecnología popular) impulsada por FBU en articulación con M. Suquilanda, } \\
\text { investigador y docente de la U. Central - Facultad de Ciencias Agrarias, uno de los primeros } \\
\text { promotores de la agricultura orgánica. Lanzan plan de rescate y revalorización de agricultura } \\
\text { andina en antiguos asentamientos Quitu - Caras, intervinieron en } 16 \text { mil Ha. }\end{array}$ \\
\hline & $\begin{array}{l}\text { Lutheran World Relieve, apoya decididamente publicaciones e intercambios regionales, } \\
\text { IIRR (Instituto Interamericano de Reconstrucción Rural), Pan para el Mundo son otras ong } \\
\text { recurrentemente mencionadas en este período. }\end{array}$ \\
\hline 1980 & $\begin{array}{l}\text { Desarrollo Juvenil Comunitario trabaja con el Cabildo Mayor de Cusubamba - Cotopaxi en la } \\
\text { implementación de técnicas orgánicas en producción de ciclo corto y huertos familiares con } \\
\text { orgánica biointensiva. }\end{array}$ \\
\hline \multirow{2}{*}{1982} & $\begin{array}{l}1982 \text { la fundación Swissaid da inicio a un largo proceso de trabajo muy intenso a favor de la } \\
\text { agricultura indígena campesina con una fuerte orientación agroecológica. }\end{array}$ \\
\hline & $\begin{array}{l}\text { Origen de la emblemática Finca Agroecológica Chaupi Molino - Puembo (F.Gangotena ) que } \\
\text { con los años es visitada por decenas de miles de agricultores y profesionales. }\end{array}$ \\
\hline \multirow{3}{*}{1983} & $\begin{array}{l}\text { Fundación Natura/CATEC impulsan proyectos de agricultura orgánica y huertos urbanos en } \\
\text { Pujilí y Salcedo - Cotopaxi. }\end{array}$ \\
\hline & $\begin{array}{l}\text { Fundación Tzantza en Morona Santiago impulsa recuperación de la chakra tradicional con } \\
\text { técnicas orgánicas. }\end{array}$ \\
\hline & $\begin{array}{l}\text { FUNDAGRO y Facultad de Agronomía de Universidad Central en Quito, Ibarra, Babahoyo y } \\
\text { Manabí, desarrollan extenso programa de investigación en técnicas orgánica de producción, } \\
\text { biodiversidad con resultados que demostraron la posibilidad de impulso de estos modelos } \\
\text { alternativos con visión comercial. }\end{array}$ \\
\hline 1986 & $\begin{array}{l}\text { Primer encuentro de granjeros orgánicos en Riobamba integrando experiencias exitosas de } \\
\text { fincas de Chimborazo, Bolívar, Tungurahua, Cotopaxi y Pichincha (impulsada por Swissaid), } \\
\text { a partir de aquí se "desata" un proceso enormemente dinamizador de visitas de intercambio, } \\
\text { integración, ampliación. }\end{array}$ \\
\hline
\end{tabular}




\begin{tabular}{|c|l|}
\hline 1986 & $\begin{array}{l}\text { Fundación Ayuda en Acción en su propuesta de desarrollo territorial en Ecuador plantea ya } \\
\text { la producción agroecológica como estrategia de intervención basándose en la metodología de } \\
\text { Sistemas Integrales de Producción Agropecuaria. }\end{array}$ \\
\hline 1987 & $\begin{array}{l}\text { Grupo Solidaridad - en el barrio Primera Constituyente de Riobamba da lugar a la primera } \\
\text { Canasta Comunitaria, 25 familias urbanas son la primera organización reconocible de } \\
\text { consumidores que se implicarán en la soberanía alimentaria y Agroecología. }\end{array}$ \\
\hline 1989 & $\begin{array}{l}\text { Fundación de PROBIO - Asociación de Productores Biológicos del Ecuador. Como su nombre } \\
\text { lo indica tenían inspiración en la agricultura biológica europea, incluso se ensayan las primeras } \\
\text { normas de producción orgánica basadas en las IFOAM. Se integrarían 250 productores de } \\
\text { Pichincha, Tungurahua, Imbabura, Cotopaxi, Azuay y Manabí. }\end{array}$ \\
\hline
\end{tabular}

Elaborado a partir de entrevistas personales y referencia de Suquilanda.

\section{Segundo momento: la evolución del paradigma agroecológico (1990 - 1996)}

A partir de los 90 del siglo XX, ocurren varios hitos históricos que en definitiva permiten la evolución de la propuesta agroecológica hacia dimensiones más sociales y políticas: Las grandes movilizaciones indígenas a principios de la década en ocasión de los 500 años de resistencia, crean un nuevo escenario de disputa ideológica y política que irrumpe en Ecuador y en toda América. En el año 92 se da la cumbre de Río de Janeiro y con ello vino el gran debate sobre desarrollo sustentable, concepto que rápidamente fue cooptado por la empresa y el mundo capitalista que buscaba darle "rostro humano y verde" a la globalización de los mercados.

En esos momentos había un profundo cuestionamiento sobre los resultados de los procesos de desarrollo ejecutados en las décadas anteriores (70 y 80). Simultáneamente, se consolidaba una fuerte crítica a los graves problemas generados por la revolución verde, a la par que se configuraba un pensamiento alternativo que orientara los enfoques y prácticas del desarrollo rural, las instituciones y organizaciones que animaban la promoción de la agroecología, que se encuentran en una necesidad de articulación y expresión nacional que da lugar a la CEA (1990 - Coordinadora Ecuatoriana de Agroecología), que si bien es una red de organizaciones no gubernamentales, como trasfondo siempre estaban las formas de resistencia indígena campesina. A decir de Lourdes Peraralbo (2004),

“...en Ecuador las corrientes ambientalistas y ecologistas que surgieron a mediados de la década de los 80 se habían polarizado entre una tendencia conservacionista (que se concentraba en la denuncia de los problemas causados por la depredación de los recurso naturales), y una tendencia modernizante (que trataba de adaptarse a la nueva demanda internacional de productos orgánicos). Empezaba a surgir la preocupación por generar una propuesta de desarrollo basada en un adecuado manejo de los RR.NN".

En 1993 se funda el Movimiento Agroecológico Latinoamericano (MAELA) que logra articular múltiples esfuerzos de integración regional, profundización del debate y puesta en práctica de los principios agroecológicos. La Agroecología incorpora, además del contenido tecnológico, una forma diferente de ver el mundo y la forma de relacionarse con él; supone un cuestionamiento a los modelos de desarrollo y una mayor implicación en la política pública que solo promueve la lógica modernizante de la agricultura y su mirada casi exclusiva a la agroexportación e integración en el mercado global.

\section{La vía campesina y el diálogo entre Agroecología y Soberanía Alimentaria}

Entre los años 1995 y 96 viene una etapa que vincula a la agroecología con una vía campesina de desarrollo, más allá de sus aportes tecnológicos. Coincide con el proceso de articulación internacional de las principales organizaciones campesinas del mundo, que dará lugar 
precisamente a la Vía Campesina Internacional (VCI) que ya ese año incorpora el paradigma de la Soberanía Alimentaria. La influencia originaria de este concepto está en la lucha de los movimientos sociales de México frente al tratado de libre comercio en norte América (Nafta); sus planteamientos fueron rápidamente acogidos por la VCI y presentados en la cumbre de la alimentación en Roma. Toda esta dinámica influyó fuertemente el debate al interior de las organizaciones campesinas ecuatorianas y las $\mathrm{ONG}^{\prime}$ s vinculadas, lo cual les permitió superar los límites del discurso del desarrollo sustentable y otras derivaciones del capitalismo verde.

El concepto de Soberanía Alimentaria venía muy marcado por la globalización de los mercados agroalimentarios y su efecto en la agricultura campesina; la agroecología por su parte venía de un énfasis en sus dimensiones tecnológicas; a medida que ambos conceptos y procesos se acercan, van madurando y encuentran una forma de potenciarse y construirse mutuamente como veremos en el período siguiente.

\begin{tabular}{|c|c|}
\hline \multicolumn{2}{|r|}{$\begin{array}{l}\text { CUADRO 3. ACTORES SOCIALES E HITOS RECONOCIBLES EN LA SEGUNDA ETAPA DE CONSTITUCIÓN DE LA } \\
\text { AGROECOLOGía EN ECUADOR }\end{array}$} \\
\hline \multirow[t]{2}{*}{1990} & $\begin{array}{l}\text { Constitución de la CEA (Coordinadora Ecuatoriana de Agroecología)-Surge como respuesta a } \\
\text { una necesidad de articulación y expresión nacional de las instituciones participantes. Lourdes } \\
\text { Peralbo (CEDIS) la primera presidenta del directorio. }\end{array}$ \\
\hline & $\begin{array}{l}\text { Proyecto UNIR-E desarrollado por la Universidad Central y fundación Kellog en norte de } \\
\text { Pichincha intenta integrar } 17 \text { mil huertos familiares orgánicos. }\end{array}$ \\
\hline 1992 & $\begin{array}{l}\text { RIAD organizan seminario sobre agriculturas sustentables y modelos de desarrollo. Se abre un } \\
\text { fuerte cuestionamiento a la noción de desarrollo (entendida como acumulación y prosperidad } \\
\text { económica) que está implícita en la modernización agraria a la que se pretende arrastrar a las } \\
\text { agriculturas campesinas. }\end{array}$ \\
\hline \multirow{5}{*}{1993} & $\begin{array}{l}\text { PRONADER (Programa Nacional de Desarrollo Rural) del Ministerio de Bienestar Social, } \\
\text { con apoyo de IICA desarrolla una extensa intervención en localidades de Tanicuchí, Toacazo, } \\
\text { Pastocalle (Cotopaxi), Espejo y Mira (Carchi), Guano (Chimborazo), Santa Isabel, Facundo } \\
\text { Vela (Bolívar) y Pangua, Jipijapa, Paján (Manabí), Daule, Tres Postes y Playas de Higuerón } \\
\text { (Guayas) generando una estrategia de agricultura sostenible, con implementación de técnicas } \\
\text { agroecológicas. }\end{array}$ \\
\hline & $\begin{array}{l}\text { En Cuenca inicia la tienda orgánica "Agrovida" que integra a } 16 \text { comunidades campesinas con } \\
\text { el apoyo del convenio MAG/CARE/PROMUSTA que ofrece hortalizas y productos libres de } \\
\text { agrotóxicos. }\end{array}$ \\
\hline & $\begin{array}{l}\text { Proyecto Salesiano "chicos de la Calle" crea la Granja Ecológica-Don Bosco, cerca de Ambato } \\
\text { - Tungurahua con producción orgánica y comercialización de diversos productos y genera un } \\
\text { proceso de capacitación a más de } 5 \text { mil familias de la provincia. }\end{array}$ \\
\hline & $\begin{array}{l}\text { Centro de Investigaciones Sociales de Loja (CISOL) desarrolla programa en el valle del río } \\
\text { Catamayo en la provincia de Loja para reducir uso de agrotóxicos y promover agricultura } \\
\text { orgánica con una granja integral demostrativa "La Vega" y varios cursos de capacitación. }\end{array}$ \\
\hline & $\begin{array}{l}\text { Unión de Organizaciones Campesinas de Quevedo-UOCQ, Unión Provincialde Organizaciones } \\
\text { campesinas de Manabí - UPOCAM, desarrollan proyectos y programas de formación y } \\
\text { producción orgánica - agroecológica con apoyo de ong como Fundación Heifer Ecuador - } \\
\text { fundación María Luisa Gomez de la Torre, siendo de las experiencias más importantes en la } \\
\text { costa ecuatoriana. }\end{array}$ \\
\hline 2000 & $\begin{array}{l}\text { Constitución de la Canasta Comunitaria UTOPIA en Riobamba (asociación de consumidores y } \\
\text { productores agroecológicos - heredera del trabajo del grupo solidaridad y germen de la futura } \\
\text { Red Nacional Mar Tierra y Canasta). }\end{array}$ \\
\hline
\end{tabular}




\title{
Tercer momento: dinamización del movimiento agroecológico y su perspectiva multidimensional en el marco de la Soberanía Alimentaria (1996 - 2006)
}

Nos referimos ahora al siguiente período cuando se amplifica y difunde la propuesta agroecológica, ahora con su enfoque integral y multidimensional. Se consolidan importantes procesos de formación campesina y capacitación para técnicos ${ }^{32}$, se incorporan con mayor dinamismo sectores académicos, paulatinamente se va superando la iniciativa de las organizaciones no gubernamentales (que hasta el momento llevaron sobre si el impulso original) y pasa a ser una demanda consustancial y práctica cotidiana de las organizaciones campesinas e indígenas desde su propias vertientes y corrientes, puesto que todo esto hace parte de las formas de resistencia campesina. Por ejemplo la Ecuarunari - Conaie retoman con fuerza sus elementos ancestrales en la producción agrícola, la Fenocin habla recurrentemente de una agricultura ancestral dinamizada ${ }^{33}$.

El diálogo entre soberanía alimentaria y agroecología gana un nuevo peldaño: la soberanía ya se entiende como derecho de los pueblos a controlar su sistema agroalimentario; es decir, la capacidad plena sobre el qué, cómo y cuándo producir y consumir. Entonces la agroecología se ofrece como una respuesta práctica que hace posible este desafío, es aquí donde asume toda su potencialidad:

\begin{abstract}
"La agricultura industrial de gran capital en su expansión desplaza a la agricultura indígena campesina (por ejemplo plantaciones bananeras o palmicultora de la costa), o la integra subordinando su fuerza de trabajo (como en la industria florícola serrana). En este contexto la agroecología puede ser la única forma de resistencia campesina porque interfiere en la lógica de dominación del capital: una finca diversificada y agroecológica ya no transfiere el valor del trabajo campesino (vía subordinación) sino que lo integra de forma autónoma; tampoco transfiere el valor de su producción agrícola (vía demanda de mercado no remunerativo) sino que logra autosatisfacción de necesidad alimentaria y mercados alternativos; finalmente rompe la dependencia tecnológica al renunciar a los paquetes propios de la revolución verde. Germina entonces una forma de desarrollo diferente para la agricultura campesina" (Larrea, entrevista personal, 2015).
\end{abstract}

Hay un dinamismo importante impulsado por varias iniciativas organizativas, proyectos de ONG's muy relevantes donde destaca el trabajo de Heifer-Ecuador que promovió procesos muy reconocibles en las provincias de Manabí, Los Ríos, Loja, Azuay, Chimborazo, Tungurahua, Cotopaxi, Pichincha, Imbabura.

Otro fenómeno importante en este período es el crecimiento notable de experiencias de mercados que viabilizan la producción campesina agroecológica en circuitos cortos de comercialización. Esto ayudó a consolidar múltiples asociaciones y redes agroecológicas en varios puntos del país y hará más notable y visible el trabajo que se viene gestando en las décadas precedentes. Particularmente la constitución de la Red Agroecológica del Austro (RAA), La Red Agroecológica de Loja (RAL), la Asociación de productores y comercialización agroecológica de Tungurahua - PACAT, la red Bioviday RESSAK en Imbabura, la Red Mar, Tierra y Canasta, La Federación de Centros Agrícolas y Organizaciones Campesinas del Litoral (FECAOL), Red de Guardianes de Semilla, entre muchas otras expresiones organizativas.

Se consolida además el intercambio regional y latinoamericano, donde pesa mucho la influencia del proceso brasileño, particularmente del MST (Movimiento de los Sin Tierra) que de forma determinada adopta la agroecología como opción política y práctica luego de vivir un notable fracaso de la agricultura convencional en los asentamientos de la reforma agraria. Esta convicción irradia a todos los movimientos campesinos del continente.

32 Particularmente el programa nacional de capacitación para técnicos y promotores agroecológicos impulsado por la CEA en asocio con el CLADES.

33 Referencia de Julio Olivera. Agroecólogo, investigador, ex coordinador técnico COPISA. 
El Primer Encuentro Nacional de Agroecología realizado en 2006 en Quito e impulsado por la CEA, expresa varios de estos puntos de debate y se apertura un nuevo momento histórico para la agroecología ecuatoriana donde aparecerán nuevos actores, nuevas fórmulas de articulación y una alta dinámica.

\section{Desarrollo agroecológico en diversos territorios y contextos ecuatorianos}

Vale aquí hacer mención a diferencias significativas del proceso de avance de la propuesta agroecológica en este período, puesto que obedece a diversos territorios, ecosistemas y contextos socio-culturales, fruto de construcciones históricas complejas que describimos en el capítulo anterior.

Seguramente en la serranía andina la potente presencia de los pueblos indígenas quichuas y su gran capacidad organizativa derivó en una adopción de modelos agroecológicos, además nutridos por la aún persistente agrobiodiversidad nativa y los conocimientos ancestrales asociados a ella. La gran cantidad de experiencias también encuentran un límite por la complejidad en el acceso a tierra y agua, que genera un fenómeno de minifundización.

En la costa fueron significativas varias experiencias y hay zonas importantes en producción diversificada campesina. Cómo ya se mencionó, el litoral ecuatoriano fue la zona preferente de expansión de estructuras de monocultivo asociadas al gran capital agroexportador y la mayor población campesina fue absorbida por esta dinámica bajo condiciones de subordinación. Sin embargo algunas familias preferían dejar de trabajar para las plantaciones (bananeras por ejemplo) donde son explotadas, obligadas a trabajar en horarios inadecuados y expuestas a fumigaciones altamente tóxicas, en su lugar se mantenían en pequeñas fincas familiares donde se cultiva "de todo un poco" y al menos se puede alimentar a la propia familia.

En la Amazonía opera otra lógica, donde la colonización ganadera, la explotación de recursos petroleros y la deforestación ejercen gran presión sobre las comunidades agrícolas ancestrales que paulatinamente se ven más expuestas y vulnerables, pero siempre en resistencia con su modelo autónomo productivo asociado al bosque húmedo amazónico.

\begin{tabular}{|c|c|}
\hline \multicolumn{2}{|r|}{$\begin{array}{l}\text { CUADRO 4. ACTORES SOCIALES E HITOS RECONOCIBLES EN LA TERCERA ETAPA DE CONSTITUCIÓN DE LA } \\
\text { AGROECOLOGÍA EN ECUADOR. }\end{array}$} \\
\hline 1995 & $\begin{array}{l}\text { Se lanza el programa nacional de capacitación para técnicos y promotores en Agroecología } \\
\text { CLADES - CEA. }\end{array}$ \\
\hline 1998 & $\begin{array}{l}\text { Lanzamiento de la escuela de diseño ecológico. Más tarde Ecoversidad de los andes } \\
\text { ecuatoriales - RGS. }\end{array}$ \\
\hline 2002 & $\begin{array}{l}\text { Primer encuentro nacional de canastas comunitarias y solidarias en Riobamba. Más tarde } \\
\text { Red Mar Tierra y Canasta. }\end{array}$ \\
\hline 2002 & Formación de la Red de Guardianes de Semilla - RGS. \\
\hline 2004 & Primer número de la revista de Agroecología ALLPA. \\
\hline 2006 & Primer encuentro nacional de Agroecología impulsado por la CEA. \\
\hline $\begin{array}{l}\text { 1ro de } \\
\text { Mayo } \\
2006\end{array}$ & $\begin{array}{l}\text { La gran marcha campesina y festival por la cultura y la vida organizado por el colectivo } \\
\text { Chimborazo con más cerca de } 5 \text { mil participantes (CEDEIN, Utopía, Aso. Productores } \\
\text { Agroecológicos de Cebadas, f. chukirahua, Red de Familias Granjeras orgánicas, F. Swissaid, } \\
\text { F. Heifer, Grupo Mashcana, grupo semilla, entre otros). }\end{array}$ \\
\hline
\end{tabular}

Elaborado a partir de entrevistas personales. 


\section{Cuarto momento: implicación política, expansión y profundización. El desafío histórico del movimiento agroecológico ecuatoriano (2006 - 2015)}

No podemos dejar de considerar el complejo contexto político social que se vive en el Ecuador hasta entrada la primera década del nuevo siglo ${ }^{34}$ cuando los movimientos sociales y políticos progresistas ecuatorianos logran conducir el escenario de disputa hacia una Asamblea Nacional Constituyente; la nueva carta magna recoge sin duda gran parte de sus demandas históricas y crea un nuevo pacto social, económico y político que hasta el momento continúa en ciernes.

Las diferentes organizaciones, $\mathrm{ONG}^{\prime} \mathrm{s}$, redes agroecológicas e instituciones articuladas alrededor de la agroecología por supuesto que se implican en este momento de alto debate y definición del sentido de la política pública.

Para Larrea el discurso agroecológico toma énfasis en un cuestionamiento a la noción de progreso y la supuesta neutralidad de la ciencia y tecnología:

"Puesto que es en la tecnología donde está el alma del capital (que es el que controla el conocimiento) no se puede pensar en un desarrollo autónomo campesino en el marco de la revolución verde, porque en definitiva se ha perdido la capacidad de decidir cómo producir; y tampoco se puede decidir qué producir, porque esto lo define la lógica de un mercado que no se puede controlar. Esa noción de desarrollo y progreso deja fuera a la agricultura campesina y comunitaria e impide la realización de la soberanía alimentaria. Es aquí donde la Agroecología toma un valor estratégico, porque implica un camino de liberación hacia el verdadero desarrollo y aporta a la consecución del Sumak Kawsay ${ }^{35}$.

Es en este marco que se constituye el Colectivo Agroecológico del Ecuador ${ }^{36}$, un renovado esfuerzo articulador de las diversas actorías sociales agroecológicas, pero desde una fórmula diferente: el enfoque de redes, y un activismo permanente que lanza campañas de sensibilización y expansión del movimiento. Estos fueron métodos efectivos para dinamizar al movimiento agroecológico, integrar nuevos actores y alcanzar nuevos territorios ${ }^{37}$. "El Colectivo ha permitido el impulso de campañas que además de promover la agroecología, permitieron visibilizar la estrecha vinculación con organizaciones y redes de consumidores, que de manera creciente fueron ampliando una estrategia más política de vinculación campo-ciudad" (Fernanda Vallejo ${ }^{38}$, entrevista personal, 2015).

El esfuerzo colectivo también imprimió sentido político a la Agroecología al integrarse al trabajo de los movimientos indígenas y campesinos que construían los contenidos del articulado constitucional y posteriormente en la formulación del la Ley Orgánica del régimen de Soberanía Alimentaria.

Algunas importantes referencias que se alcanzan en la Constitución Política de la República del Ecuador se consideran en el siguiente cuadro.

\begin{tabular}{|c|l|}
\hline Artículo & \multicolumn{1}{|c|}{ Contenido } \\
\hline 281 & $\begin{array}{l}\text { La Soberanía Alimentaria constituye un objetivo estratégico y una obligación del Estado } \\
\text { para garantizar que las personas, comunidades, pueblos y nacionalidades alcancen la } \\
\text { autosuficiencia de alimentos sanos y culturalmente apropiados de forma permanente. }\end{array}$ \\
\hline
\end{tabular}

34 Nos referimos a la serie de levantamientos indígenas y movilizaciones populares que entre 1995 y 2002 terminaron con los derrocamientos de tres gobiernos, y que pusieron freno a los procesos del ALCA, TLC y la imposición de políticas neoliberales.

35 Este es el sentido histórico político que resume a la nueva constitución ecuatoriana.

36 Socios fundadores 2007: UTOPIA y la red Mar Tierra y Canasta (MTC); Red de Guardianes de Semillas (RGS); asociación de productores biológicos del Ecuador - PROBIO; CEA (coordinadora ecuatoriana de agroecología). Impulsados pon el apoyo de Heifer-Ecuador, VECO (cooperación belga) y Vecinos Mundiales (actualmente Ekorural).

37 La primera campaña "come sano, seguro y soberano" tuvo repercusiones en todo el país y su imagen pública "la pacha" se convirtió en el emblema de la Soberanía Alimentaria y la Agroecología.

38 Socióloga, permanente acompañante de las organizaciones indígenas y campesinas, Fundación Heifer - Ecuador. 


\begin{tabular}{|c|c|}
\hline $\begin{array}{c}281 \\
\text { letra } \mathrm{C}\end{array}$ & $\begin{array}{l}\text { Con la finalidad de alcanzar la Soberanía Alimentaria el Estado ecuatoriano se responsabiliza a: } \\
\text { c) fortalecer la diversificación y la introducción de tecnologías ecológicas y orgánicas en la } \\
\text { producción agropecuaria. } \\
\text { f) Promover la preservación y recuperación de la agrobiodiversidad y de los saberes } \\
\text { ancestrales vinculados a ella, así como el uso, la conservación e intercambio de semillas. } \\
\text { h) Asegurar el desarrollo de la investigación científica y la innovación tecnológica apropiada } \\
\text { para garantizar la soberanía alimentaria. } \\
\text { j) Fortalecer el desarrollo de organizaciones y redes de productores y de consumidores, así } \\
\text { como las de comercializaciones y distribución de alimentos que promuevan la equidad entre } \\
\text { espacios rurales y urbanos. }\end{array}$ \\
\hline 401 & $\begin{array}{l}\text { Se declara al Ecuador libre de cultivos y semillas transgénicas. } \\
\text { Excepcionalmente y solo en caso de interés nacional debidamente fundamentado por la } \\
\text { Presidencia de la República y aprobado por la Asamblea Nacional, se podrán introducir. }\end{array}$ \\
\hline 410 & $\begin{array}{l}\text { Es de interés público y prioridad nacional la conservación del suelo, es especial su capa fértil. } \\
\text { Se establecerá un marco normativo para su protección y uso sustentable que prevenga la } \\
\text { degradación, en particular la provocada por la contaminación, la desertificación y la erosión. }\end{array}$ \\
\hline
\end{tabular}

En Mayo del 2009 se publica la Ley Orgánica del Régimen de Soberanía Alimentaria (LORSA) que genera el marco de políticas para una reforma agraria y considera elementos claves de la protección de la agrobiodiversidad, fomento agroecológico, comercio alternativo, consumo responsable entre otras normas que explicamos en el siguiente cuadro.

\begin{tabular}{|c|l|}
\hline Artículo & \multicolumn{1}{c|}{ Contenido } \\
\hline 3 & $\begin{array}{l}\text { Obligaciones del estado.- Incentivar el consumo de alimentos sanos, nutritivos de origen } \\
\text { agroecológico y orgánico, evitando en lo posible la expansión del monocultivo y la } \\
\text { utilización de cultivos agroalimentarios en la producción de biocombustibles, priorizando } \\
\text { siempre el consumo alimenticio nacional. }\end{array}$ \\
\hline $7-8$ & $\begin{array}{l}\text { Agrobiodiversidad y Semillas.- El Estado así como las personas y las colectividades } \\
\text { protegerán, conservarán los ecosistemas y promoverán la recuperación, uso, conservación } \\
\text { y desarrollo de la agrobiodiversidad y de los saberes ancestrales vinculados a ella.... } \\
\text { El Estado así como las personas y las colectividades promoverán y protegerán el uso, } \\
\text { conservación, calificación e intercambio libre de toda semilla nativa. }\end{array}$ \\
\hline 14 & $\begin{array}{l}\text { Fomento a la producción Agroecológica y Orgánica.- El Estado estimulará la producción } \\
\text { agroecológica, orgánica y sustentable, a través de mecanismos de fomento, programas de } \\
\text { capacitación líneas especiales de crédito y mecanismos de comercialización en el mercado } \\
\text { interno y externo, entre otros. } \\
\text { En sus programas de compra pública dará prioridad a las asociaciones de productores } \\
\text { agroecológicos. }\end{array}$ \\
\hline 21 & $\begin{array}{l}\text { Comercialización interna.- Los gobiernos autónomos descentralizados proveerán de la } \\
\text { infraestructura necesaria para el intercambio y comercialización directa entre pequeños } \\
\text { productores y consumidores, en beneficio de ambos, como una nueva relación de economía } \\
\text { social y solidaria. }\end{array}$ \\
\hline 27 & $\begin{array}{l}\text { El Estado, con el fin de disminuir y erradicar la desnutrición y malnutrición, incentivará } \\
\text { el consumo de alimentos nutritivos preferentemente de origen agroecológico y orgánico, } \\
\text { mediante el apoyo a su comercialización, la realización de programas de promoción y } \\
\text { educación nutricional para el consumo sano. }\end{array}$ \\
\hline
\end{tabular}


El mismo año la LORSA dio lugar a la conformación de la Conferencia Plurinacional e Intercultural de Soberanía Alimentaria, organismo del poder ciudadano que intenta promover y dar seguimiento a las nuevas políticas para la agricultura y alimentación. En 2012 se logra la presentación pública de la propuesta de Ley de Agrobiodiversidad y Fomento Agroecológico inspirada por el trabajo de más de 2500 personas (principalmente productores agroecológicos), y por primera vez la voz del movimiento agroecológico llegó a la Asamblea Nacional Legislativa en la histórica sesión 190, debate que hasta la fecha actual sigue inconcluso.

\section{Agroecología y el debate público sobre el modelo agrario}

Pero este ejercicio de participación ciudadana obtuvo otros logros importantes, y quizás uno de los de mayor relevancia es que la agroecología irrumpe en el debate público y se inserta en el imaginario colectivo. Es fácilmente reconocible en diversos medios de comunicación (múltiples entrevistas, publicaciones periódicas, campañas de difusión); en presentaciones públicas; eventos múltiples (destaca el FIAGORA y las jornadas agroecológicas académicas, diversos encuentros agroecológicos); manifestaciones multitudinarias (especialmente el ya tradicional Festival Nacional y Marcha Campesina por la Soberanía Alimentaria del 16 de octubre que ya camina a su quinta edición); implicación mayor de las universidades y centros académicos (al menos 12 centros universitarios desarrollan actividades relacionadas, nuevos cursos, programas de maestría, las jornadas académicas agroecológicas). Se multiplican los circuitos económicos agroecológicos (ferias, tiendas y otras modalidades se registran en la guía agroecológica que visibiliza a más de 130 iniciativas en todo el país) ${ }^{39}$; se activa un movimiento de consumidores por la agroecología que genera grandes campañas de sensibilización (la nueva campaña colectiva "que rico es comer sano y de mi tierra" mantiene gran dinamismo).

Por otro lado, no solamente en la Asamblea Nacional Legislativa, sino en diferentes instancias públicas se debate y se presentan voces a favor de un cambio estructural de modelo agrario. Gobiernos locales también intentan integrar este paradigma, caso emblemático el del gobierno de Pichincha que aprobó en 2014 la ordenanza de fomento agroecológico, actualmente construye mecanismos de aplicación. El gobierno de Pastaza ya ha incorporado un importante presupuesto de fomento agroecológico, aun sin disponer de una ordenanza. A través de la COPISA se lograron 13 resoluciones de juntas parroquiales a favor de la soberanía alimentaria y agroecología, algunas de las cuales están en plena ejecución. ${ }^{40}$ Dentro del ministerio de Agricultura se ha constituido la Dirección General de Redes Comerciales, que es una de las instancias de mayor fomento de la propuesta agroecológica.

Estratégicamente el discurso del Colectivo Agroecológico intenta posicionar la propuesta agroecológica como "Agricultura del futuro", a modo de disputa de sentidos frente al renovado impulso de la agricultura industrial y su derivación biotecnología moderna (transgénicos) ${ }^{41}$. El debate sobre la introducción de organismos transgénicos en la agricultura ecuatoriana ha sido parte importante de la cuestión agraria en los últimos años; la prohibición constitucional (art. 401) se encuentra permanentemente cuestionada por intereses económicos y cientistas, sin embargo se ha logrado recientemente la aplicación obligatoria del etiquetado a productos transgénicos importados, lo cual está generando presión desde el consumidor hacia la industria alimentaria, efecto que bien puede estimular la vía agroecológica.

39 Se pude revisar la guía nacional de ferias agroecológicas en www.quericoes.com.

40 Referencia de Julio Olivera - ex coordinador técnico COPISA.

41 Hay que señalar que la política pública, en contradicción con las disposiciones constitucionales y legales, está aún lejos de reorientar el modelo agrario hacia la propuesta agroecológica, y en oposición ha crecido significativamente el impulso al agronegocio y expansión del monocultivo industrial. 


\section{Agroecología, Soberanía Alimentaria y Economía Solidaria}

Finalmente otro elemento importante en el relato actual, tiene que ver con una reflexión que vincula Agroecología, Soberanía Alimentaria y Economía Solidaria. Tomando como referencia el estudio realizado en 2012 sobre producción y comercialización realizado por el Colectivo Agroecológico mediante el estudio de consultoría COPISA sobre comercialización agroecológica ${ }^{42}$, encontramos que existirían actualmente al menos 140 circuitos agroecológicos de comercialización que integran aproximadamente a 15 mil familias productoras y más de 20 mil familias de consumidores estables. Cuando se empiezan a consolidar estos circuitos económicos agroecológicos, a través de fórmulas de comercio directo consumidor productor, comercio justo y otras prácticas similares, descubrimos que la agroecología y la soberanía alimentaria solo caben en una sociedad solidaria, construida precisamente en el pilar de relaciones económicas de nuevo tipo, más inclusivas, equitativas y cuyo fin no es la acumulación monetaria, sino la satisfacción de necesidades auténticas y legítimas de personas que respetan los límites naturales del ecosistema tierra, y que se respetan entre sí como parte de una sociedad solidaria. Otras redes como el Movimiento de Economía Social y Solidaria del Ecuador MESSE, expresa esta relación y se articula fraternalmente con el Colectivo Agroecológico.

\begin{tabular}{|c|c|}
\hline \multicolumn{2}{|c|}{$\begin{array}{l}\text { CUADRO 5. ACTORES SOCIALES E HITOS RECONOCIBLES EN EL PERÍODO RECIENTE DE CONSTITUCIÓN DE LA } \\
\text { AGROECOLOGÍA EN ECUADOR }{ }^{43}\end{array}$} \\
\hline $\begin{array}{l}\text { 1ro mayo } \\
2006\end{array}$ & $\begin{array}{l}\text { Cinco mil personas en la marcha regional por la Soberanía, la Agroecología y la vida en } \\
\text { Riobamba. Evento precursor del nacimiento del MESSE y colectivo agroecológico. }\end{array}$ \\
\hline \multirow[b]{2}{*}{2007} & $\begin{array}{l}\text { Primera feria de economía solidaria en Cuenca - evento precursor del Movimiento de } \\
\text { Economía Social y Solidaria del Ecuador (MESSE). }\end{array}$ \\
\hline & $\begin{array}{l}\text { Se constituye el Colectivo Agroecológico del Ecuador }{ }^{44} \text {, que se expresa en dos dimensiones: } \\
\text { la campaña nacional por la Soberanía Alimentaria (come sano seguro y soberano) que } \\
\text { permite la rearticulación y expansión de la Agroecología a nuevos territorios y nuevos } \\
\text { actores; y la implicación en políticas públicas. }\end{array}$ \\
\hline 2008 & $\begin{array}{l}\text { Proceso constituyente: el colectivo agroecológico, MESSE y otros actores se integran } \\
\text { al esfuerzo de los movimientos indígenas y campesinos para construir los contenidos } \\
\text { del articulado constitucional relacionados con temas de soberanía alimentaria (reforma } \\
\text { agraria, agua, tierra, semilla, fomento agroecológico), economía solidaria, derechos de la } \\
\text { naturaleza, entre otros. }\end{array}$ \\
\hline $\begin{array}{l}\text { Mayo } \\
2009\end{array}$ & Entra en vigencia la ley orgánica del Régimen de Soberanía Alimentaria. \\
\hline Julio 2009 & $\begin{array}{l}\text { Muisne - Esmeraldas: En la Asamblea de la Red Nacional Mar, Tierra y Canasta (MTC } \\
\text { filial del colectivo agroecológico y MESSE) se define la participación directa en la futura } \\
\text { Conferencia Plurinacional e Intercultural de Soberanía Alimentaria (COPISA). }\end{array}$ \\
\hline $\begin{array}{l}\text { Agosto } \\
2009\end{array}$ & Se alcanza la representación nacional de consumidores y productores ante la COPISA. \\
\hline
\end{tabular}

42 Análisis situacional de experiencias de comercio alternativo en el ecuador para el diseño de políticas del sistema nacional de comercialización para la soberanía alimentaria - COPISA - 2012.

43 Información recabada a partir de entrevistas con diversas personalidades.

44 Socios fundadores: UTOPIA y la red Mar Tierra y Canasta (MTC); Red de Guardianes de Semillas (RGS); asociación de productores biológicos del Ecuador - PROBIO; CEA (coordinadora ecuatoriana de agroecología). Impulsados con el apoyo de Heifer Ecuador, VECO (cooperación belga) y Vecinos Mundiales (actualmente Ekorural). 


\begin{tabular}{|c|c|}
\hline $\begin{array}{l}2010 \\
2012\end{array}$ & $\begin{array}{l}\text { Proceso de creación del proyecto de ley de Agrobiodiversidad, Semillas y Fomento } \\
\text { Agroecológico ( } 2500 \text { agricultores participan del debate y proceso creativo impulsado por } \\
\text { COPISA). }\end{array}$ \\
\hline $\begin{array}{l}2010 \\
\text { Quito }\end{array}$ & $\begin{array}{l}\text { Foro Internacional sobre políticas públicas para la Agrobiodiversidad y el Fomento } \\
\text { Agroecológico (impulsado por COPISA) }\end{array}$ \\
\hline $\begin{array}{l}\text { Abril } \\
2012\end{array}$ & $\begin{array}{l}\text { Primera movilización nacional y marcha por la soberanía alimentaria en Guayaquil } \\
\text { impulsada por FECAOL (se considera un hito fundamental por la presencia multitudinaria } \\
\text { del movimiento agroecológico en la capital comercial del ecuador; este es signo visible de } \\
\text { la etapa de expansión del movimiento). }\end{array}$ \\
\hline 2012 & $\begin{array}{l}\text { Acuerdo Nacional Colectivo Agroecológico y MESSE (Movimiento de Economía Social y } \\
\text { Solidaria) para la cooperación y acción conjunta. }\end{array}$ \\
\hline $\begin{array}{l}\text { Octubre } \\
2012 \\
\text { Guayaquil }\end{array}$ & $\begin{array}{l}\text { Segundo FIAGORA (Foro Internacional sobre Agroecología y agricultura orgánica) } \\
\text { impulsado por FECAOL, Colectivo Agroecológico y MESSE. }\end{array}$ \\
\hline $\begin{array}{l}\text { Julio } \\
2012\end{array}$ & $\begin{array}{l}\text { Primer debate del proyecto de ley de Fomento Agroecológico en el pleno de la Asamblea } \\
\text { Nacional Legislativa (sesión 190) - es la primera vez que la voz del movimiento } \\
\text { agroecológico alcanza el debate político en la máxima instancia de esta función del Estado. }\end{array}$ \\
\hline $\begin{array}{l}2012 \\
2013\end{array}$ & $\begin{array}{l}\text { Constitución de la Comisión Nacional de Consumidores por la Soberanía Alimentaria, } \\
\text { primera expresión de organización autónoma de las y los consumidores en defensa de la } \\
\text { Agroecología y el consumo responsable. }\end{array}$ \\
\hline $\begin{array}{l}\text { Junio } \\
2013\end{array}$ & $\begin{array}{l}\text { Primeras jornadas académicas agroecológicas impulsadas por el colectivo agroecológico } \\
\text { y universidades en } 5 \text { provincias - precursor de la iniciativa SOCLA Ecuador. (Sociedad } \\
\text { Científica Latinoamericana de Agroecología Capítulo Ecuador). }\end{array}$ \\
\hline $\begin{array}{l}\text { Octubre } \\
2013\end{array}$ & $\begin{array}{l}\text { Segunda movilización nacional y marcha campesina en Guayaquil por la soberanía } \\
\text { alimentaria y contra los transgénicos impulsada por colectivo agroecológico y FECAOL - } \\
\text { Lanzamiento de la campaña nacional por el consumo responsable y solidario "que rico es } \\
\text { comer sano y de mi tierra" impulsada por el movimiento de consumidores. }\end{array}$ \\
\hline 2013 & Publicación de la Ley Orgánica para la Economía Popular Solidaria. \\
\hline 2014 & Publicación de la Ordenanza de Fomento Agroecológico del Gobierno de Pichincha. \\
\hline $\begin{array}{l}\text { Junio } \\
2014\end{array}$ & $\begin{array}{l}\text { Segundas jornadas académicas agroecológicas impulsadas por Colectivo Agroecológico, } \\
\text { SOCLA y universidades de } 6 \text { provincias. }\end{array}$ \\
\hline \multirow{2}{*}{$\begin{array}{l}\text { Octubre } \\
2014\end{array}$} & $\begin{array}{l}\text { Tercera movilización nacional y marcha campesina en Guayaquil por la Soberanía } \\
\text { alimentaria y Agroecología impulsada por colectivo agroecológico y FECAOL. }\end{array}$ \\
\hline & $\begin{array}{l}\text { Cayambe Segundo Encuentro Nacional Agroecológico impulsado por la CEA, constitución } \\
\text { de la Comisión Nacional Campesina Agroecológica. }\end{array}$ \\
\hline $\begin{array}{l}\text { Octubre } \\
2015\end{array}$ & $\begin{array}{l}\text { Cuarto festival nacional y marcha campesina por la soberanía alimentaria y agroecología - } \\
\text { Guayaquil, impulsado por FECAOL. }\end{array}$ \\
\hline $\begin{array}{l}\text { Julio } \\
2016\end{array}$ & $\begin{array}{l}\text { Terceras Jornadas Agroecológicas impulsadas por Colectivo Agroecológico, SOCLA, } \\
\text { universidades y organizaciones en } 8 \text { localidades del país. }\end{array}$ \\
\hline $\begin{array}{c}\text { Octubre } \\
2016\end{array}$ & $\begin{array}{l}\text { Primera Cumbre Agraria de los Pueblos impulsada por CONAIE, Ecuarunari, FECAOL, } \\
\text { CNA y diversos movimientos sociales. Movimiento agroecológico tiene un importante rol } \\
\text { y posicionamiento. }\end{array}$ \\
\hline
\end{tabular}




\section{Tendencias y desafíos en el horizonte}

Según varios criterios recabados, dado el contexto nacional en pleno desarrollo, se pueden avizorar al menos dos escenarios probables.

Una tendencia a un neo desarrollo capitalista en el campo, incluso más agresiva que en otros períodos históricos. La idea de progreso que se ofrece a la familia campesina apunta a su incorporación o subordinación a la empresa agraria de gran capital, a la consolidación del agronegocio; en otras palabras, la oferta es convertir a los campesinos en obreros agrícolas asalariados del gran capital, o en proveedores de materia prima para la industria agroalimentaria; en esta dinámica no hay futuro ni cabida para una economía campesina autónoma, basada en la diversificación y la producción agroecológica, fórmula que garantizaría la producción de alimentos apropiados y seguros. Esto profundizará la tendencia hacia el desplazamiento y des-campesinización generalizada. Probablemente encontraremos también que el movimiento campesino y agroecológico va a resistir en estas condiciones adversas, que le impedirán desarrollarse con mayor amplitud, pero como siempre encontrará medidas y mecanismos para mantener los espacios alcanzados.

Un segundo escenario, menos oscuro en el horizonte, reflejaría al menos un equilibrio entre el impulso aparentemente incontenible de los sistemas industriales y expansión del gran capital agrario, pero con un movimiento campesino y agroecológico más dinámico, articulado, en expansión y profundización. Si tan solo se lograra la aplicación efectiva de las normas constitucionales y legales logradas en 2008 - 2009 a favor de la soberanía alimentaria y agroecología, ya viviríamos otra realidad en los campos. Un detonante importante podrían ser los problemas de salud pública y la conciencia ciudadana que cada vez es más cercana a la noción de alimentación saludable y diversa; al parecer crece la preocupación pública sobre el origen y calidad de sus alimentos y esto lo relaciona con la estructura agraria, potencialmente podría abrirse este escenario de enlace campo - ciudad por la agroecología. Este es un punto clave, puesto que la producción campesina no puede crecer sin réditos concretos, tampoco crecerá solo con mercados elitarios o nichos restringidos. La producción campesina agroecológica tiene que alcanzar la dimensión de alimento popular, este es un gran desafío ¿cómo lo hacemos? La respuesta puede estar en una amplia reflexión y puesta en práctica de circuitos económicos solidarios, un diálogo profundo entre los sectores populares del campo y la ciudad.

En todo caso, los escenarios futuros dependen de las acciones en el presente, y aquí nos atrevemos a mencionar algunos desafíos que devienen para el movimiento agroecológico.

Expansión: hace referencia al necesario crecimiento que requiere un movimiento dinámico. La agroecología debe cooptar cada vez más territorio rural, ser una expresión notable en el paisaje agrícola ecuatoriano, más allá de la finca o la parcela. Lo fundamental es considerar el control sobre el territorio con sus implicaciones en el manejo de recursos naturales, cuencas hídricas, ordenamiento territorial, ecosistemas naturales circundantes, culturas y economía local. Crecer también implica relacionarse con otros actores, principalmente aquellos que van en dirección a la defensa de la naturaleza, reforma agraria y soberanía alimentaria, en particular aquellas organizaciones indígenas y campesinas a quienes la agroecología enriquecería y daría sentido integral a sus plataformas de lucha.

También debe incorporar nuevos actores tradicionalmente poco vinculados a la agroecología, como aquellos en los sectores académicos de la agronomía, también sectores relacionados a los temas alimentarios y de salud pública, pero quizás lo más importante es que la agroecología necesita una expansión urbana, expresión que sin duda puede dar oxígeno a las complejas luchas campesinas que requieren dinamizarse, redimensionarse, reconstruirse. En este sentido pueden haber varios caminos, sea por la vía de crear agriculturas urbanas, sea expandiendo circuitos económicos solidarios (ferias, mercados) y por supuesto por la vía de movilizar a ese actor social llamado "familia consumidora" que paulatinamente crezca en sensibilidad, conciencia y afecto 
hacia la agricultura familiar campesina, y que actúe determinadamente en el cambio de patrones y hábitos de consumo y compra alimentaria a favor de la agroecología. El consumidor urbano debiera ser el aliado natural del movimiento agroecológico y campesino.

Profundización: queremos significar aquí el desafío de no perder las nociones y principios fundamentales del paradigma agroecológico, particularmente de su multidimensionalidad tecnológica, ambiental, social y política. Como anunciamos en el primer capítulo, es fácil sufrir la cooptación, simplificación y superficialización del auténtico proceso agroecológico. Es común

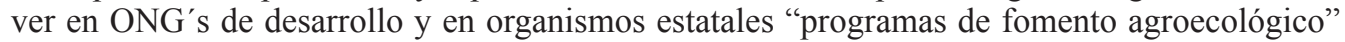
que desfiguran los auténticos propósitos de la agroecología: promover "huertitos caseros", repartir bioinsumos como soluciones mágicas, o reducir "un poquito" el uso de agroquímicos, sirve tan solo para proyectar una imagen de supuesta coherencia ambiental, pero no confrontan los problemas agudos, profundos y complejos de la agricultura campesina y la política agraria.

Articulación: significa adaptarse a la heterogeneidad y complejidad de las fuerzas que componen este movimiento, sus diversas formas de articulación y organización local, regional y nacional, y romper las barreras ideológicas y geográficas de los Estados. Buscar complementariedad y por sobre todo respeto y tolerancia a su diferencia interna, es otro desafío gigantesco. Más aún si lo que queremos es enfrentar con éxito a la brutal expansión de la agroindustria, su derivación biotecnológica y su entramado en el gran capital. Muy a menudo nos estrellamos con límites creados humana y artificialmente por nuestro ego personal y organizativo; magnificamos nuestras diferencias políticas o de visiones secundarias y así perdemos el horizonte común y las posibilidades de cooperación y construcción colectiva. No es deseable crear una sola gran unidad homogénea o superestructurada, pero si es indispensable tener canales de diálogo entre actores diversos, entre redes e instituciones, y lograr colaboración en acciones concretas y estratégicas, no duplicar esfuerzos, ni "marcar territorio". El desafío es demasiado grande para enfrentarlo divididos, y seguramente esta sea la tarea más difícil y compleja, y al mismo tiempo la más decisiva en vista del escenario adverso que enfrentaremos en los próximos años.

\section{Palabras finales}

Quizás podamos tomar lecciones e inspirarnos de la misma fuente que nos permite construir y diseñar nuestros bellos sistemas agroecológicos: recordemos que en nuestras fincas agroecológicas no hay "malezas" que erradicar, puesto que todo es útil aunque en principio no sepamos bien para qué; así mismo entre compañeros y compañeras tenemos que encontrar la sinergia y el lugar adecuado, no pensar que al primer desencuentro somos indeseables. Tampoco buscamos la homogeneidad y el monocultivo, tal vez por eso no debamos añorar una uniforme y única estructura organizativa; en la chakra buscamos siempre la asociación, la complementariedad, no todos se junta con todos, hay relaciones funcionales y otras que no funcionan, pero todo puede ser aporte en alguna medida y en algún momento. En las relaciones entre compañeros y compañeras deberíamos procurar tanto o más cuidado que el que tenemos con nuestras plantitas o animalitos; y quizás, igual o más respeto que el que dispensamos para nuestra pacha mama.

La promoción de la agroecología no intenta disimular o maquillar la crisis agroalimentaria, estamos desafiados a transformar los sistemas agroalimentarios, la forma de producir y consumir alimentos. Proponemos un nuevo modelo agrario que pueda enfrentar el cambio climático, la pobreza rural, que recupere la fuerza y la vitalidad de los agroecosistemas, que genere productividad y alimentos saludables para un mundo en crecimiento. La agroecología se ofrece como respuesta para la desesperanza campesina y muestra un camino de liberación de toda estructura de dominación; es el camino para recuperar el control sobre los sistemas agroalimentarios; es decir, la Soberanía Alimentaria de los pueblos. ¡Ésta es la Agricultura del futuro en el presente y debemos optar por ella sin más dilaciones, con decisión y compromiso revolucionario! 


\section{Bibliografía}

Asamblea Nacional Constituyente. 2008, Constitución Política de la República del Ecuador.

Asamblea Nacional Legislativa. 2009, Ley Orgánica del Régimen de Soberanía Alimentaria.

AGROCALIDAD, MAGAP. 2013, Normativa para el fomento y regulación de la producción orgánica, biológica y ecológica, Agencia Ecuatoriana de Aseguramiento de la Calidad del Agro.

Comisión Consumidores para la Soberanía Alimentaria. 2014, Guía de Ferias Agroecológicas del Ecuador.

COPISA. 2012, Propuesta de ley orgánica de Agrobiodiversidad, Semillas y Fomento Agroecológico, Conferencia plurinacional e Intercultural de Soberanía Alimentaria.- Comisión técnica de Agrobiodiversidad.

Ehlers, E. 2001, Corrientes y Tendencias en la Agricultura Ecológica, Libro del estudiante. VII Curso Sobre Agroecología y Desarrollo Rural, CLADES -Consorcio Latinoamericano de Agroecología y Desarrollo.

HEIFER. 2005, Agroecología: una apuesta necesaria, memorias del taller andino de Agroecología, Ecuador.

HEIFER, Ministerio de Agricultura, Ganadería, Acuacultura y Pesca. 2015, La Agroecología está presente.- mapeo de productores agroecológicos y del estado de la Agroecología en la sierra y costa ecuatoriana, Ecuador.

GDDL, Escuela de Formación de Liderazgos Democráticos. 2000, Historia del Ecuador, compilación. Quito. Publicación interinstitucional

Gortaire, R. 2014, "Respuestas del pasado para la Agricultura del futuro - Sistemas Ingeniosos de Patrimonio Agrícola-SIPAN", FAO, Ministerio Cultura y Patrimonio del Ecuador (Documento en Revisión).

Colectivo Agroecológico del Ecuador. 2012-2015, Memorias Asambleas.

Peña, D. Valverde, M. y Bellmont, 2012. P. Estudio sobre circuitos cortos de comercialización en el Ecuador Consultoría COPISA - Conferencia Plurinacional e Intercultural de Soberanía Alimentaria.

Peralbo, Lourdes. 2004, Diagnóstico Situacional de la CEA, CEA, Coordinadora Ecuatoriana de Agroecología. Documento insterinstitucional. Quito

Restrepo, J. y Hensel, J. 2013, El ABC de la agricultura orgánica.- fosfitos y panes de piedra, Editorial FERIVA. Cali. Colombia,

Suquilanda, M. 1998, "Hacia una Agricultura Sostenible en el Ecuador", en: Separata Técnica - IICA, No. 23, Ecuador.

\section{Entrevistas y consultas personales}

Francisco Gangotena, Antropólogo y Agricultor, Finca Agroecológica Chaupi Molino en Puembo- Pichincha, exdirector de la Fundación Swissaid. 05/06/2015

Fernando Larrea, Antropólogo, investigador, ex - director Fundación Heifer Ecuador. 10/07/2015

Manuel Suquilanda, Investigador y docente, ex decano Facultad Ciencias Agrarias Universidad Central. $22 / 04 / 2015$

Fernanda Vallejo, Socióloga, miembro de la Fundación Heifer Ecuador. 30/04/2015

Maestro Cesar Ayol, Agricultor, propietario de la Finca Agroecológica el Molino - Guamote. 12/06/2015

Patricio Bravo, ex presidente de la Red Agroecológica del Austro. 25/04/2015

Pedro de la Cruz, dirigente campesino, ex presidente de la FENOCIN - Federación Nacional de Organizaciones Campesinas, Indígenas y Negras. Ex asambleísta constituyente y actual Parlamentario Andino. 10/05/2015

Julio Olivera, investigador agroecólogo, ex coordinador técnico de la conferencia plurinacional e intercultural de soberanía alimentaria - COPISA. 22/02/2015. 